\title{
Comparison of CMIP6 and CMIP5 Model Performance in Simulating Historical Precipitation and Temperature in Bangladesh: A Preliminary Study
}

Mohammad Kamruzzaman ( $\nabla$ milonbrri@gmail.com )

Bangladesh Rice Research Institute https://orcid.org/0000-0001-6640-8082

Shamsuddin Shahid

Bangladesh Rice Research Institute

ARM Towfiqul Islam

Bangladesh Rice Research Institute

Syewoon Hwang

Bangladesh Rice Research Institute Jaepil Cho

Bangladesh Rice Research Institute

Md. Asad Uz Zaman

Bangladesh Rice Research Institute

Minhaz Ahmed

Bangladesh Rice Research Institute

Md. Mizanur Rahman

Bangladesh Rice Research Institute

Md. Belal Hossain

Bangladesh Rice Research Institute

\section{Research Article}

Keywords: Temperature, Precipitation, Bangladesh, Climate change, CMIP6

Posted Date: February 24th, 2021

DOl: https://doi.org/10.21203/rs.3.rs-233789/v1

License: (c) (1) This work is licensed under a Creative Commons Attribution 4.0 International License.

Read Full License 
Version of Record: A version of this preprint was published at Theoretical and Applied Climatology on July 5th, 2021. See the published version at https://doi.org/10.1007/s00704-021-03691-0. 
Comparison of CMIP6 and CMIP5 model performance in simulating historical precipitation and temperature in Bangladesh: A preliminary study

Abstract

The relative performance of global climate models (GCMs) of phases 5 and 6 of the Coupled Model Intercomparison Project (CMIP5 and CMIP6, respectively) was assessed in this study based on their ability to simulate annual and seasonal mean rainfall and temperature over Bangladesh for the period 1977-2005. The multiple statistical metrics were used to measure the performance of the GCMs at 30 meteorological observation stations. Two robust multicriteria decision analysis methods were used to integrate the results obtained using different metrics for an unbiased ranking of the GCMs. The results revealed MIROC5 as the most skilful among CMIP5 GCMs and ACCESS-CM2 among CMIP6 GCMs. Overall, a significant improvement in CMIP6 MME compared to CMIP5 MME was noticed in simulating rainfall over Bangladesh at annual and seasonal scales. CMIP6 MME also showed significant reduction in maximum and minimum temperature biases over Bangladesh. However, systematic wet and cold biases still exist in CMIP6 models for Bangladesh. CMIP6 GCMs showed higher spatial correlation with observed data compared to CMIP5 GCMs, but higher difference in terms of standard deviations and centered root mean square errors, indicating better performance in simulating geographical distribution but lower performance in simulating spatial variability of most of the climate variables for different timescales. In terms of Taylor skill score, the CMIP6 MME showed higher performance in simulating rainfall but lower performance in simulating temperature compared to CMIP5 MME for most of the timeframes. The findings of this study suggest that the added value of rainfall and temperature simulations in CMIP6 models is incompatible with the climate models used in this research.

Keywords: Temperature; Precipitation; Bangladesh; Climate change; CMIP6

\section{Introduction}

Appraisal of climate change impacts on precipitation and temperature has become essential due to increased climaterelated extreme events such as floods and droughts. General Circulation Models (GCMs) are vital for climate change impact assessment. However, the major challenge in climate change projections and impact assessments is the selection of an appropriate subset of GCMs. GCM simulations are associated with large uncertainties arising from different sources including model resolution, mathematical formulation, initial assumptions, and calibration processes that restrict the use of all GCMs for reliable projections of climate at the regional or local scale (Hijmans et al. 2005; Foley 2010; Chen et al. 2011; Northrop 2013; Khan et al. 2018a; Salman et al. 2018; Sun et al. 2018; Ahmed et al. 2019c). Therefore, a subset of GCMs is suggested by removing the less skilled models in simulating observed climate to minimize uncertainties in projection (Lutz et al. 2016; Lin and Tung 2017; Khan et al. 2018b; Salman et al. 2018; Ahmed et al. 2019b).

It is also suggested that GCMs should be selected on the basis of their performance in simulating the climate variable of interest to reduce the uncertainty in the projection of that variable (Gleckler et al. 2008; McMahon et al. 2015; Lutz et al. 2016; Sa'adi et al. 2017; Salman et al. 2018). The assessment of the ability of GCMs to simulate different climatic parameters, such as surface mean temperature, precipitation, summer monsoon rainfall and sea surface temperature, has been demonstrated in different regions of the world (Perkins et al. 2007; Maxino et al. 2008; Johnson et al. 2011). No specific approach is widely recommended for the selection of GCMs. Besides, there are no well-established guidelines for the selection of appropriate GCMs. However, it is expected that the selected GCM will be able to replicate the mean, spatial variability, and distribution of historical climate (Ahmed et al. 2020). It is also suggested that the selection of GCMs based on their performance in simulating both rainfall and temperature as both 
are equally required for most of the climate change studies (Ahmed et al. 2019a; Nashwan and Shahid 2020; Shiru et al. 2020)

GCM simulations disseminated through different phases of coupled model intercomparison project (CMIP) are vital sources for quantitative climate projection over the twenty-first century (Baker and Huang 2014; Eyring et al. 2016). The CMIP phase 3 (CMIP3) GCM simulations (Meehl et al. 2007) were used to prepare the fourth assessment report of IPCC (Solomon, S. et al. 2007). The CMIP5 models were the improved version of CMIP3 models in terms of physical processes and network accuracy (Taylor et al. 2012). Comparison of CMIP3 and CMIP5 models showed better performance of CMIP5 GCMs in simulating observed climate in many regions and large-scale atmospheric circulations that define regional climate (Sperber et al. 2013; Ogata et al. 2014).

A new coordinated series of climate experiments have recently been carried out under the umbrella of Phase 6 of CMIP. In many ways, the CMIP6 GCMs differ from previous generations, including finer spatial resolutions, enhanced parameters of the cloud microphysical process and additional Earth system processes and components such as biogeochemical cycles and ice sheets (Eyring et al. 2019). The vital difference between CMIP5 and CMIP6 is the future scenario. CMIP5 projections are available on the basis of 2100 radiative forcing values for four GHG concentration pathways (van Vuuren and Riahi 2011). In contrast, CMIP6 uses socioeconomic pathways (SSPs) with the CMIP5 scenarios premises (O'Neill et al. 2014). Therefore, the shared SSPs are considered more realistic future scenarios (Song et al. 2021). Another vital update of CMIP6 is the development and support of the intercomparison model, focusing on biases, processes, and climate models' feeds (Heinze et al. 2019). Several studies have been conducted to compare the performance of CMIP6 GCMs with CMIP5 GCMs in different regions (Rivera and Arnould 2020; Gusain et al. 2020a). Both better and poorer performance of CMIP6 GCMs compared to their earlier versions in CMIP5 has been reported in simulating different climate variables and phenomena in different regions. (Gusain et al. 2020b) compared the performance of CMIP6 and CMIP5 models in simulating Indian summer monsoon rainfall and reported that the added value of CMIP6 models in summer rainfall simulation was inconsistent. (Nie et al. 2020) showed that CMIP6 models provide more accurate measures of the magnitude of global temperature extremes compared to CMIP5. (Rivera and Arnould 2020) showed better capability of CMIP6 models in simulating declining precipitation and droughts in Southwestern South America. (Wu et al. 2019) have found important enhancements in CMIP6 models in simulating tropospheric air temperature and circulation in East Asia at global and regional levels and climatic variability at different time intervals including the diurnal rainfall cycle, annual shifts in sea levels and the long-term surface air temperature trend in the Pacific Ocean. Different studies also showed higher warming and more sensitivity of CMIP6 GCMs compared to their previous version (Tokarska et al. 2020; Zelinka et al. 2020). Overall, the studies suggest different performance of CMIP6 GCMs compared to CMIP5 GCMs in different regions. This can be attributed to the spatial variability of GCM uncertainty (Tiwari et al. 2014). Therefore, it is necessary to assess the ability of newly released CMIP6 models to simulate the current climate and assess their performance relative to CMIP5 in different regions.

It remains unclear how well the new CMIP6 models simulate the climate response to anthropogenic forcing in Bangladesh. The comparison of CMIP6 and CMIP5 is important for the various sectors of this highly vulnerable country for which policy makers have been engaged in developing adaptation alternatives based on the climate change 
impacts assessed by the CMIP5 simulations. Any major improvement in the projection of the CMIP6 model relative to that of CMIP5 models will alter the probable impact and alternatives to adaptation (Shashikanth et al. 2014). However, the CMIP6 datasets have not been examined by any analysis to investigate precipitation and temperature changes in Bangladesh so far. Therefore, it is of great interest to systematically evaluate the performance of CMIP6 GCMs in climate simulation across Bangladesh and to compare their performance with the previous generation of GCMs.

The motivation of this study is to compare the climate models of CMIP6 with the previous climate models of CMIP5 for the simulation of precipitation and temperature climatology in Bangladesh for the period $1977 \square 2005$. The common GCMs of both CMIP5 and CMIP6 were ranked based their performance in replicating annual and seasonal climatology to facilitate selection of suitable subsets of GCMs of CMIP5 and CMIP6 for climate change impact assessment in Bangladesh and streamline the adaptation measures adopted based CMIP5 scenarios with the new SSP scenarios. The performance assessment of CMIP6 models would also provide important information such as their biases for different climate variables in different time scales which are essential for making decisions on effective adaptation measures.

\section{Study area and data}

\subsection{Study area}

Bangladesh located between latitude $20.34 \square 26.38^{\circ} \mathrm{N}$ and longitude $88.01 \square 92.41^{\circ} \mathrm{E}$ is bordered by India in three sides (west, north, and northeast), Myanmar in the southeast and Bay of Bengal in the South. The country is a low-lying flood plain with three major river systems: the Ganges, the Brahmaputra and the Meghna, commonly known as the GBM river system. The elevation of the country varies from near to mean sea level (msl) in the south to about $105 \mathrm{~m}$ above msl in the north (Fig. 1). However, there are few uplifted land and hills in the northeast and southeast of the country. A warm and humid climate characterized by wide seasonal variation in rainfall dominates the country. Mos of the rainfall $(\sim 70 \%)$ occurs during the monsoon (June-September). Between the pre-monsoon (March-May) and post-monsoon (October-November) seasons, the rest of the rainfall is distributed. The winter is fairly dry (DecemberFebruary). About $20 \%$ is flooded annually due to the flat topography and heavy rainfall during the monsoon. The recorded inundation was as high as $70 \%$ of the total land in extreme cases, as in 1998. The mean annual temperature of Bangladesh is about $25^{\circ} \mathrm{C}$. A noticeable regional variation in rainfall and temperature is seen in Bangladesh, despite being located in a monsoon-dominated area (Khan et al. 2019). The rainfall varies from nearly $1600 \mathrm{~mm}$ in the northwest to more than $4000 \mathrm{~mm}$ in the northeast, and the mean temperature varies between 11 and $29^{\circ} \mathrm{C}$ in winter, and between 21 and $34^{\circ} \mathrm{C}$ during summer (Kamruzzaman et al. 2019). Bangladesh frequently suffers from different kinds of natural disasters such as flash floods, monsoon floods, droughts, cyclone and storm surges, riverbank erosion, and urban floods. It is recognized globally as one of the most vulnerable countries to natural hazards and climate change.

\subsection{Models, Data sets, and Analysis method}


The study compared the performance of 11 GCMs of CMIP5 with their updated versions in CMIP6. The monthly simulation of rainfall (R), maximum temperature (Tmax) and minimum temperature (Tmin) of CMIP5 and CMIP6 GCMs were retrieved from the data portals of Earth System Grid Federation (ESGF). For each model, only the historical realisation was analyzed. The performance assessment was conducted for the period 1977 $\square 2005$, considering the availability of observed data for that period. The list of GCMs and their developing organization is given in Table 1.

Rainfall and temperature data recorded at 35 in-situ meteorological stations were collected from Bangladesh Meteorological Department (BMD). The common period of the collected data was 29 years, ranging from 1977 to 2005. After the quality control and homogeneity test, 30 stations were selected for the present study. The locations of the stations over the map of Bangladesh is shown in Figure 1. It can be observed that the stations are distributed over the country and therefore, it can be considered that these 30 stations can well represent the climate of Bangladesh. Some missing values were observed in the collected dataset. However, the amount of missing data was $<2 \%$. The average values of neighbouring stations were used in replace of the missing data.

\section{Methodology}

The performance of the GCMs was evaluated based on their capability in reconstructing annual and seasonal R, Tmax and Tmin climatology of Bangladesh for the period 1977 $\square 2005$. Observed data is available from 1977 while the CMIP5 hindcast is available until 2005. Therefore, the period 1977】2005 was selected for performance assessment. The GCM simulations were interpolated to 30 observation locations using inverse distance weighting method. The annual and seasonal mean of GCM and observed P, Tmax, and Tmin for the period 1977\2005 was estimated at all the thirty station locations. These values were compared using Kling-Gupta Efficient (KGE) metric to assess the performance of the GCMs. For example, the performance of a GCM in simulating annual rainfall was evaluated by comparing the annual mean of GCM rainfall and annual mean of observed rainfall at 30 locations. In a similar way, the performance of GCMs for all three climate variables (P, Tmax, and Tmin) for five timescales (annual and four seasons) was computed. Therefore, total 15 (3 variables $\times 5$ seasons) KGE values were generated for each GCM to present its performance.

Ranking of GCMs based on their performance in simulating multiple variables in different timeframes is a challenging task because a GCM may show various degrees of accuracy for different variables and timeframes. Therefore, multi-criteria decision analysis (MCDA) algorithms were used to generate a composite index from 15 KGE measurements. In this study, two MCDA algorithms were used to avoid the bias that may arise from a single MCDA, which are Global Performance Indicator (GPI) (Despotovic et al. 2015) and Compromise programming index (CPI) (Raju and Kumar 2020). The GCMs were then ranked according to descending order of GPIs and ascending order to

CPI. The simple average of the ranks obtained using GPI and CPI was used to provide the final rank of GCMs. Details of the methods used for performance evaluation and ranking of GCMs are presented in following subsections. 


\subsection{Kling-Gupta efficiency (KGE.)}

The KGE (Gupta et al. 2009) (Kling et al. 2012) is an objective statistical metric that uses three measures, correlation, bias, and similarity in variance to assess similarity between two datasets. The multi-component essence of KGE has made it a composite index to be used alone for a more holistic and balanced goodness-of-fit evaluation (Koch et al. 2018). KGE is expressed as follow:

$K G E=1-\sqrt{(r-1)^{2}+(\gamma-1)^{2}+(\beta-1)^{2}}$

$\gamma=\frac{\mu_{s}}{\mu_{o}}$

$\beta=\frac{\alpha_{s} / \mu_{o s}}{\alpha_{o} / \mu_{o}}$

where $r$ is Pearson's correlation between GCM simulation (s) and observed data (o), $\beta$ represents the bias that is normalized by the standard deviation of the observed data. $\gamma$ is a fraction of the variation coefficient reflecting spatial variability, $\mu$ and $\sigma$ represent the mean and standard deviation of the simulation of GCM (s) and observed data (o), respectively. The values of KGE vary between 1 and $-\infty$, where 1 indicates a perfect agreement. The KGE is a robust metric and is also commonly used as a metric for spatial assessment (Zambrano-Bigiarini et al. 2017; Ahmed et al. 2019a; Nashwan et al. 2019; Nashwan and Shahid 2020)

\subsection{Global Performance Indicator (GPI)}

GPI (Despotovic et al. 2015) combines the effects of individual statistical indicators to provide a single measure. The GPI has been used in many other fields as an effective multicriteria decision analysis (MCDA) tool (Behar et al. 2015; Despotovic et al. 2015). The distance between the normalized value of a performance indicator and the median of the normalized values of the same performance indicator is calculated.

$G P I_{i}=\sum_{j=1}^{n}\left(y_{i j}-\bar{y}_{j}\right)$

where $y_{j}$ is the median of the normalized values of the performance indicator $j, n$ is the number of performance indicators, and $\mathrm{y}_{\mathrm{i}, \mathrm{j}}$ is the normalized value of the performance indicator $\mathrm{j}$ for the model $\mathrm{i}$. A higher value of GPI indicates better performance.

\subsection{Compromise Programming Index (CPI)}

The CPI also combines multiple performance metrics into a single metric like GPI, but in a different way. The distance between the standardized value of a performance indicator and the ideal value of the same indicator is calculated (Raju and Kumar 2014):

$C P I=\left[\sum_{j=1}^{n} \mathrm{r}\left|\mathrm{x}_{j}^{1}-\mathrm{x}_{j}^{*}\right| p^{2}\right]^{1 / p}$

where $j$ means statistical index; $\mathrm{x}_{j}^{1}$ is the normalized value of index $j$; $\mathrm{x}_{j}^{*}$ is the normalized ideal value of index $j$, and $\mathrm{p}$ is the parameter which was considered 1 in this study for measuring linear Euclidean distance from the ideal value. A lower value of CPI indicates better performance of a GCM. 


\subsection{Relative performance of CMIP5 and CMIP6 GCMs}

Multi-model ensembles (MMEs) of CMIP5 and CMIP6 GCMs were prepared by a simple averaging method. The performance of individual GCMs and their MMEs for CMIP5 and CMIP6 were compared to show the relative performance of the GCMs of those two intercomparison projects. Taylor diagram (Taylor 2001) was prepared for visual presentation of relative performance. The Taylor diagram provides a concise statistical summary of the degree of correlation (SCC: spatial correlation coefficient (SCC)), centered root-mean-square error (CRMSE), and the ratio of spatial standard deviation (SD) and thus, provides a composite comparison of model performance.

The quantitative assessment of relative performance of CMIP6 and CMIP5 models was done using Tylor skill score ((Taylor 2001),

Skill $=\frac{(1+\mathrm{R})^{2}}{(\mathrm{SDR}+[1 / \mathrm{SDR}])^{2}}$

where R represents correlation between model simulation and observation, and SDR is the ratio of the standard deviation (SD) of model simulation and observation.

\section{Results}

\subsection{Evaluation of CCM}

The KGEs estimated for CMIP5 and CMIP6 models in simulating annual, pre-monsoon, monsoon, post-monsoon, winter rainfall (R), maximum temperature (Tmax), and minimum temperature (Tmin) climatology in Bangladesh are presented in Table 2. The performance of the GCMs was found to vary significantly for different climate variables and timescales. For example, ACCESS1-0 of CMIP5 performed best in simulating annual Tmin and Tmax while MIROC5 in simulating R. MIROC5 performed best in simulating monsoon R but performed badly in estimating premonsoon R. Similar disparity in performance of CMIP6 GCMs can also be observed from Table 2.

A large disparity in performance of a model in CMIP5 and CMIP6 was also noticed. For example, MIROC5 performed best among the CMIP5 GCMs in simulating observed rainfall, but it was ranked 3 among CMIP6 GCMs. This inconsistency between CMIP5 and CMIP6 was more in simulating seasonal mean climatology compared to annual mean climatology. It was not possible to compare the relative performance of different GCMs due to large variability in their performance in simulating $\mathrm{R}$, Tmax and Tmin for different timescales. Therefore, GPI and CPI were used to generate composite metrics and ranking of GCMs.

\subsubsection{Ranking of GCMs}

The estimated GPI and CPI values for each of the CMIP5 and CMIP6 GCMs are presented in Table 3. Ranking of the GCMs based on average values of GPI and CPI are also presented in the table. As the GCMs were ranked based on composite indices, it can be considered that the ranks indicate their performance in reproducing the spatial characteristics of all climate variables for all timeframes. Results revealed MIROC5 as the most skillful CMIP5 GCM 
and ACCESS-CM2 as the most skillful among CMIP5 GCMs. On the other hand, IPSL-CM5A-LR and MPI-ESM12-LR showed the poorest performance among the CMIP5 and CMIP6 GCMs, respectively.

\subsection{Comparison of CMIP5 and CMIP6 models}

\subsubsection{Precipitation}

Fig. 2 and Fig. S1-S4 compares the annual and seasonal precipitation climatology simulated by the CMIP5 and CMIP6 MMEs with observed climatology. The observed rainfall (both annual and seasonal except winter) in Bangladesh is highest in the east and gradually decreases to the west (Fig. 2a, S1a, S2a, S3a, S4a). This spatial feature was reasonably reproduced by both CMIP5 and CMIP6 MMEs (Fig. 2, S1-4, (b, c)). However, underestimation in annual, premonsoon, post-monsoon rainfall and overestimation in monsoon and winter rainfall, especially in the hilly eastern region was noticed (Fig. 2, S1-4 (b, c)).

The spatial pattern in biases of CMIP5 and CMIP6 MMEs were almost similar. The dominant rainfall underestimation was in the northeastern and southeastern hilly areas. This indicates that the effect of high topography on precipitation is still a challenge in climate modelling. In CMIP5, the underestimation in those regions for annual, monsoon, pre-monsoon, post-monsoon, and winter precipitation was over 6 mm.day ${ }^{-1}, 3$ mm.day ${ }^{-1}, 1$ mm.day ${ }^{-1}, 0.4$ mm.day ${ }^{-1}$, and $0.1 \mathrm{~mm} \cdot \mathrm{day}^{-1}$, respectively, which were high than the underestimated values of CMIP6 models, particularly in the eastern hilly areas (Fig. 2, S1-4 (d, e)).

CMIP6 MME showed improvement compared to CMIP5 MME in terms of bias in annual, pre-monsoon, and post-monsoon rainfall in most of the country. However, the bias in CMIP6 MME for monsoon and winter was higher than CMIP6 MME. Notably, an improvement was observed in CMIP6 over CMIP5 in simulating the spatial variability of mean rainfall over the high rainfall receiving areas. A significant improvement in CMIP6 models and their MME has been reported over Central and North India by Jain et al. (2019). High rainfall over these areas was underestimated by most CMIP5 models.

The performance of each GCM and MME for both CMIP5 and CMIP6 in producing observed rainfall is presented using Taylor diagram in Fig. 3. The figure shows a large and dispersed between-model distribution for both CMIP6 and CMIP5, and therefore, large variability in bias and RMSE. The SSC of CMIP6 MME was 0.61 (Fig. 3a), whereas it was 0.33 for CMIP5. Overall, CMIP6 models showed a better ability to simulate the spatial pattern of annual precipitation in Bangladesh. The SCCs of CMIP6 MME for pre-monsoon (0.57), monsoon (0.62), and postmonsoon (0.74) were greater than that of CMIP5 MME. However, it was inferior for winter (0.22). The SCC intervals for different models were relatively consistent for pre-monsoon, monsoon, post-monsoon, and summer. However, most models showed a poor correlation in winter. This may be due to low and erratic rainfall during winter which often difficult to capture in climate models.

Normalized standard deviations (centered root mean square error, CRMSE) are 0.30-1.16 (0.78-1.5) for the annual mean, 0.37-5.16 (0.96-5.15) in winter, 0.18-1.37 (0.66-1.39) in pre-monsoon, 0.31-1.00 (0.73-1.41) in 
monsoon, and 0.41-1.39 (0.85-1.52) in post-monsoon. This means that most CMIP6 GCMs poorly simulate the spatial variability of rainfall climatology over Bangladesh. Moreover, the CMIP6 MME underestimated observed SD more than CMIP5 MME except for pre-monsoon. The lower SD of most the models compared to observed SD indicates an underestimation of the spatial variability of rainfall by the models.

Compared to CMIP5 GCMs, SSCs were higher, but SDs and CRMSEs were further away from the observation for CMIP6 GCMs (Fig. 3). This indicates a relative superiority CMIP6 GCMs in reproducing geographical distribution but inferiority in simulating spatial variability. A higher SD represents high extreme precipitation events (Mohsenipour et al. 2018; Attogouinon et al. 2020). Since CMIP5 MME has a smaller SD than that of CMIP6 except for pre-monsoon, the likelihood of extreme precipitation events is higher in CMIP6 GCMs.

Fig. 4 shows the Taylor skill score of CMIP5 and CMIP6 models in reproducing annual and seasonal precipitation. It was found that skill score varies with seasons. However, the skill scores of CMIP6 models were higher than that of their previous versions in CMIP5 for all the seasons except winter.

The number of CMIP6 GCMs show a better (poorer) score than their corresponding CMIP5 versions was 8 (2) for annual and post-monsoon, 9(2) for monsoon, 7(3) for pre-monsoon, and 4(4) for winter (Fig. 4). ACCESSCM2 (0.99) and INM-CM5-0 (0.99) for annual, ACCESS-CM2 (1.00) and ACCESS-ESM1-5 (1.00) for monsoon, ACCESS-CM2 (0.98) for pre-monsoon, CanESM5 (1.00) for post-monsoon, and CNRM-CM6-1 (0.94) and INMCM5-0 (0.94) for winter were the highest performing models of CMIP6. The most remarkable improvement among the models was found for IPSL-CM6A-LR (0.82) relative to IPSL-CM5A-LR (0.01) in pre-monsoon season. The skill score of CMIP6 MME was 0.78 for post-monsoon, and 0.54 for winter, which were larger than the CMIP5 MME $(0.50$ and 0.19, respectively), indicating better performance of CMIP6 MME compared to CMIP5 MME. Almost similar scores were found for annual (0.37) and monsoon (0.35) timeframes. However, CMIP6 MME showed a lower score than CMIP5 MME for pre-monsoon. Overall, it can be remarked that the performance of GCMs in simulating rainfall climatology of Bangladesh has increased marginally from CMIP5 to CMIP6. This indicates that they are inherent in improving critical physical systems using a single model study (Wu et al., 2019).

\subsubsection{Maximum Temperature}

Fig. 5 and Fig.(S5-S8) present the Tmax climatology simulated by CMIP5 and CMIP6 MMEs and their biases in annual and seasonal timeframes. The annual and seasonal Tmax is highest over the western part of Bangladesh which gradually decreases to the east (Fig. 5a, S5a, S6a, S7a, S8a) except for the winter season. In winter, the maximum temperature is higher in the north and lower in the south. Both the CMIP5 and CMIP6 MMEs were able to reproduce this spatial attribute of Tmax reasonably. However, it underestimated Tmax during post-monsoon and winter seasons throughout the country. The Tmax was also partly underestimated for annual, monsoon, and pre-monsoon seasons, especially in the hilly eastern area, and partly overestimated in rest of the country (Fig. 5, S5-8 (b, c)). 
The Tmax biases in CMIP5 and CMIP6 MMEs were found dominant in the northwest, northeast, and southeastern hilly areas. The underestimations in CMIP5 MME for annual $\left(0.98-2.98^{\circ} \mathrm{C}\right)$, monsoon $\left(0.36-1.89^{\circ} \mathrm{C}\right)$, pre-monsoon $\left(0.03-2.52^{\circ} \mathrm{C}\right)$, post-monsoon $\left(1.13-4.02^{\circ} \mathrm{C}\right)$, and winter temperature $\left(0.93-4.3^{\circ} \mathrm{C}\right)$ were higher than that for CMIP6, particularly in eastern hilly areas (Fig. 5, S5-8 (d, e)). The highest negative bias was found for winter and postmonsoon seasons due to cold bias. Overall, the results indicate greater reproducibility of annual, post-monsoon, and winter Tmax in most areas by CMIP6 MME compared to CMIP5 MME.

Fig. 6 shows the performance of each GCM and MME of both CMIP5 and CMIP6 on Taylor diagram. The CMIP6 models performed well in simulating the spatial pattern of seasonal Tmax. The SCC of CMIP6 MME (CMIP5 MME) was 0.67 (0.63), 0.77 (0.65), 0.73 (0.73), 0.28 (0.30) and 0.59 (0.53) for annual, pre-monsoon, post-monsoon and winter seasons, respectively. This indicates a greater or similar performance of CMIP6 models compared to CMIP5 models. For individual models, the correlation coefficients were ranged from 0.23 to 0.72 for the annual, $0.31 \square 0.82$ for monsoon, $0.31 \square 0.76$ for pre-monsoon, $-0.04 \square 0.42$ for post-monsoon, and $-0.07 \square 0.79$ for winter. The simulation to observed SD ratios were larger than 1 for both CMIP6 and CMIP5 MMEs. This implies that the models overestimated annual and seasonal variabilities of Tmax. This ratio in CMIP6 MME was highest for monsoon (2.22) and lowest for post-monsoon (1.15). All the models also showed larger variabilities in monsoon Tmax ranging from 1.51 to 4.14. Compared to CMIP5 GCMs, SSCs for CMIP6 GCMs were higher, but SDs and CRMSEs were further away from observation (Fig. 6). This indicates a relative superiority of CMIP6 GCMs in reproducing the geographical distribution of Tmax but inferiority in simulating the spatial variability of Tmax.

Fig.7 presents the skill scores of CMIP5 and CMIP6 models in reproducing annual and seasonal Tmax. The skill scores of CMIP6 models and MME were found lower than that estimated for their corresponding CMIP5 models. Number of CMIP6 GCMs showed a better (poorer) score than their CMIP5 parents were 2(9) for annual, 3(8) for postmonsoons, 4(7) for monsoon, 3(7) for pre-monsoon, and 2(9) for winter. Among the CMIP6 models, the greatest improvement was noticed for INM-CM5-0 and MRI-ESM2-0 for all the timeframes.

\subsubsection{Minimum Temperature}

Fig. 8 and Fig. (S9-S12) compare the Tmin climatology simulated by CMIP5 and CMIP6 MME with observed climatology in annual and seasonal timescales. The observed annual and seasonal Tmin is highest in the south which decreases gradually towards the north except for monsoon (Fig. 8a, S9a, S10a, S11a, S12a). This spatial feature was reasonably reproduced by both the CMIP5 and CMIP6 MMEs. However, CMIP5 MME underestimated and CMIP6 MME overestimated annual, pre-monsoon and monsoon Tmin, while both CMIP5 and CMIP6 MMEs underestimated post-monsoon and winter Tmin (Fig. 8, S9-12 (b, c)).

The biases in CMIP5 and CMIP6 MMEs were found dominant in the northwest. The CMIP5 MME estimated Tmin in the northwestern regions for post-monsoon and winter more than $5^{\circ} \mathrm{C}$ less compared to CMIP6 estimated Tmin (Fig. 8, S9-12 (d, e)). This implies CMIP6 MME showed improvement in cold bias compared to CMIP5 MME.

Fig. 9 shows the performance of each GCM and MMEs of both CMIP5 and CMIP6 sets in producing observed Tmin based on Taylor diagram. The SCC of CMIP6 MME (CMIP5 MME) were 0.74 (0.78), 0.77 (0.83), 
$0.70(0.69), 0.50(0.54)$, and $0.69(0.66)$ for annual, pre-monsoon, monsoon, post-monsoon, and winter, respectively. This indicates better performance of CMIP6 GCMs compared to CMIP5 GCMs for all seasons except for winter. The SSC of the individual models were ranged from 0.33 to 0.61 for annual, -0.15 to 0.70 for monsoon, 0.34 to 0.71 for pre-monsoon, 0.19 to 0.59 for post-monsoon, and 0.22 to 0.63 for winter. The interval of annual and seasonal SSCs for CMIP6 was closer than that for CMIP5. The SSC intervals for different models are relatively consistent for premonsoon, monsoon, post-monsoon, and summer. However, most models showed poor SSC in post-monsoon.

The simulated SDs of both CMIP6 and CMIP5 models were larger than the observed SD for all timescales, implying that the models overestimated annual and seasonal Tmin variabilities. Large variability was noticed for monsoon compared to other seasons. The SCCs, SDs, and CRMSEs were further away from observation in CMIP6 GCMs compared to CMIP5 GCMs (Fig. 9). This indicates inferior performance of CMIP6 GCMs compared to CMIP5 GCMs in replicating both geographical distribution and spatial variability.

Fig.10 presents CMIP5 and CMIP6 model's skill scores in reproducing annual and seasonal Tmin. It was found that the skill scores of CMIP6 MMEs were lower than that of CMIP5 MMEs for all seasonal except postmonsoon. The number of CMIP6 GCMs showed a better (lower) skill score compared to their CMIP5 parents was 2(9) for annual, post-monsoons and monsoons, 3(8) for pre-monsoons and winter. Among the CMIP6 models, the most significant improvement in simulating Tmin was observed for INM-CM5-0 and MRI-ESM2-0.

\section{Discussions}

Performance of GCMs of CMIP5 and CMIP6 in simulating rainfall and temperature at annual, pre-monsoon, monsoon, post-monsoon, and winter timescales over Bangladesh for the period 1977-2005 was evaluated in this study. Both the CMIP5 and CMIP6 MMEs were able to reproduce spatial pattern of rainfall climatology in Bangladesh reasonably. However, both the MMEs underestimated annual, pre-monsoon, post-monsoon rainfall and overestimated monsoon and winter rainfall, especially in the hilly eastern region. The coarser resolution of GCMs does not capture the orographic effects and local landmass changes that affect spatial variability and rainfall distribution (Shashikanth et al. 2014; Jain et al. 2019). Therefore, high resolution of climate information for the practical application over Bangladesh and the needs of further spatial downscaling.

The wet bias in annual precipitation was higher over the northeastern hilly regions of the country. The models simulated higher than the observed rainfall in the northeastern region during monsoon and winter. This can be the possible causes of wet bias in annual rainfall. Most of the CMIP6 and CMIP5 models simulated the southwest monsoon signals, and the easterly wind flows from the Bay of Bengal in winter and monsoon. However, precipitation uncertainties in monsoon and winter were more than those in pre-monsoon and post-monsoon due to the easterly wind system and the orographic effect.

Overall, an improvement in CMIP6 over CMIP5 was observed in simulating the spatial variability of mean precipitation over the high rainfall receiving areas. The result was found consistent with the finding of (Jain et al. 2019) in India. They reported a significant improvement over Central and North India in CMIP6 models and their MME, where the majority of CMIP5 models underestimated high precipitation over these areas. Compared to CMIP5 GCMs, SCCs of CMIP6 GCMs were higher (except winter), but SDs and CRMSEs were further away from the 
observation (Fig. 3). This indicates a relative superiority of CMIP6 GCMs in reproducing the geographical distribution but inferiority in simulating spatial variability. (Duan et al. 2013) indicated that the incorporation of sulfate aerosol indirect effects could enhance the ability of CMIP6 models to simulate the annual precipitation cycle, but a large bias remains. Considering the systematic model biases, more cautions should be taken in using GCM projections for impact assessment over Bangladesh.

The cold bias was a common error for most models in the previous generations of CMIPs (Ipcc 2013) (Guo et al. 2013). It was also found to exist in CMIP6. (Zhu and Yang 2020) showed a general cold bias in annual mean temperature in China. (Almazroui et al. 2020) showed a general cold bias in annual mean temperature in south Asian countries, including Bangladesh. This study presents that CMIP6 models generally underestimated the maximum and minimum temperature with a cold bias, especially in the cold season (post-monsoon and winter season). However, CMIP6 MME showed improvement in cold bias compared to CMIP5 MME in post-monsoon and winter Tmax and Tmin over most of the country. SCCs of CMIP6 MMEs were higher than the CMIP5 GCMs, but SDs and CRMSEs were farther away from the observation (Fig. 6). It indicates a relative dominance in replicating geographical distribution of Tmax but inferiority in replicating spatial variability. (Almazroui et al. 2020) also demonstrated that some models overestimated the annual mean temperature. Previous studies based on CMIP5 models showed that the performance of GCM varies significantly and depends on the variable being considered. (Kamworapan and Surussavadee 2019; Pathak et al. 2019). In the present analysis, the skill score of most CMIP6 GCMs including their MME was lower than that for CMIP5 at both annual and seasonal scales. However, some individual models performed well in CMIP6 compared to their earlier version in CMIP5. The results emphasize the need of further research for scientific understanding of the origins of systematic model biases in Bangladesh.

Several CMIP6 models showed better simulations of temperature or precipitation compared to CMIP5. IMMCM5 from CMIP5 and MRI-ESM2 from CMIP6 performed best in simulating temperature over the country. Contrary to this finding, the temperature simulation capability of CanESM5 over the Tibetan Plateau was among the top five CMIP5 models, reported by(Chen et al. 2017). Likewise, IPSL-CM5A-LR from CMIP5 was the optimal model for simulating precipitation in China (Zhou and Li 2002). (Zamani et al. 2020) reported that the outcomes of HadGEM2ES from CMIP5 and CESM2 from CMIP6 were best in simulating precipitation in northeastern Iran. The uncertainties, errors, and topographic differences may be possible reasons in large geographical variation in optimal model. Some explicit parameter control experiments are required to detect the main factor influencing the errors and uncertainties over Bangladesh in individual models. The weaker performance of new-generation models indicates that confidence is not compatible with larger scales in the model's ability to simulate surface temperature and precipitation on a regional scale. More attention should be paid in choosing CMIP6 models rather than merely replacing the corresponding CMIP5 model without verification. The bias-correction is also needed to improve the utility of CMIP6 for further applications. The seasonal changes of intertropical convergence zone (ITCZ) bias and their differences among CMIP5 and CMIP6 models are significant; however, they are not examined in this paper and should be examined in the future. 


\section{Conclusion}

The ability of eleven CMIP6 climate models was compared with their previous versions in CMIP5 in simulating annual and seasonal mean rainfall and temperature over Bangladesh for the period 1977-2005. The results showed MIROC5 as the most skilful among CMIP5 GCMs and ACCESS-CM2 among CMIP6 GCMs in reproducing annual and seasonal rainfall and temperature of Bangladesh. The CMIP6 GCMs showed better skill in simulating the geographical distribution of temperature and precipitation climatology over Bangladesh. The performance was relatively better for rainfall than for temperature. However, systemic wet biases in CMIP6 were found to exist in high precipitation receiving areas. CMIP6 MME also showed significant improvement in terms of maximum and minimum temperature biases, but systemic cold biases in cold seasons are still there (post-monsoon and winter). SCCs of CMIP6 GCMs were higher compared to that for CMIP5 GCMs, but SDs and CRMSEs were farther away from the observation for most of the CMIP6 GCMs. This indicates a relative dominance of CMIP6 GCMs in replication geographical distribution of temperature but inferiority in simulating spatial variability in temperature. However, for minimum temperature, relative inferiority was noticed for in simulating both geographical distribution and spatial variability. The Taylor skill score showed a higher score for CMIP6 MME in precipitation simulation but a lower score for temperature compared to CMIP5 MME in most of the timeframes. However, some individual models showed good agreement with observation in simulating the quantity and spatial distribution of rainfall.

This preliminary study has some limitations and can be regarded as a possible field of near-future research that heralds the beginning of a new age of high-resolution climate models for CMIP6. A similar evaluation could be carried out after the release more CMIP6 models to gain a greater insight into the changes within CMIP6 models in commensurate to climate valuables over Bangladesh. 


\section{REFERENCE}

Ahmed K, Sachindra DA, Shahid S, et al (2020) Multi-model ensemble predictions of precipitation and temperature using machine learning algorithms. Atmospheric Research.

https://doi.org/10.1016/j.atmosres.2019.104806

Ahmed K, Sachindra DA, Shahid S, et al (2019a) Selection of multi-model ensemble of general circulation models for the simulation of precipitation and maximum and minimum temperature based on spatial assessment metrics. Hydrology and Earth System Sciences. https://doi.org/10.5194/hess23-4803-2019

Ahmed K, Shahid S, Sachindra DA, et al (2019b) Fidelity assessment of general circulation model simulated precipitation and temperature over Pakistan using a feature selection method. Journal of Hydrology. https://doi.org/10.1016/j.jhydrol.2019.03.092

Ahmed K, Shahid S, Wang X, et al (2019c) Evaluation of gridded precipitation datasets over arid regions of Pakistan. Water (Switzerland). https://doi.org/10.3390/w11020210

Almazroui M, Saeed S, Saeed F, et al (2020) Projections of Precipitation and Temperature over the South Asian Countries in CMIP6. Earth Systems and Environment. https://doi.org/10.1007/s41748-02000157-7

Attogouinon A, Lawin AE, Deliège JF (2020) Evaluation of general circulation models over the upper oueme river basin in the republic of Benin. Hydrology. https://doi.org/10.3390/hydrology7010011

Baker NC, Huang HP (2014) A comparative study of precipitation and evaporation between CMIP3 and CMIP5 climate model ensembles in semiarid regions. Journal of Climate. https://doi.org/10.1175/JCLI-D-13-00398.1

Behar O, Khellaf A, Mohammedi K (2015) Comparison of solar radiation models and their validation under Algerian climate - The case of direct irradiance. Energy Conversion and Management. https://doi.org/10.1016/j.enconman.2015.03.067

Chen J, Brissette FP, Leconte R (2011) Uncertainty of downscaling method in quantifying the impact of climate change on hydrology. Journal of Hydrology. https://doi.org/10.1016/j.jhydrol.2011.02.020

Chen X, Liu Y, Wu G (2017) Understanding the surface temperature cold bias in CMIP5 AGCMs over the Tibetan Plateau. Advances in Atmospheric Sciences. https://doi.org/10.1007/s00376-017-6326-9

Despotovic M, Nedic V, Despotovic D, Cvetanovic S (2015) Review and statistical analysis of different global solar radiation sunshine models. Renewable and Sustainable Energy Reviews

Duan A, Hu J, Xiao Z (2013) The tibetan plateau summer monsoon in the CMIP5 simulations. Journal of Climate. https://doi.org/10.1175/JCLI-D-12-00685.1

Eyring V, Bony S, Meehl GA, et al (2016) Overview of the Coupled Model Intercomparison Project Phase 6 (CMIP6) experimental design and organization. Geoscientific Model Development. https://doi.org/10.5194/gmd-9-1937-2016 
Eyring V, Cox PM, Flato GM, et al (2019) Taking climate model evaluation to the next level. Nature Climate Change. https://doi.org/10.1038/s41558-018-0355-y

Foley AM (2010) Uncertainty in regional climate modelling: A review. Progress in Physical Geography. https://doi.org/10.1177/0309133310375654

Gleckler PJ, Taylor KE, Doutriaux C (2008) Performance metrics for climate models. Journal of Geophysical Research Atmospheres. https://doi.org/10.1029/2007JD008972

Guo Y, Dong WJ, Ren FM, et al (2013) Surface air temperature simulations over China with CMIP5 and CMIP3. Advances in Climate Change Research. https://doi.org/10.3724/SP.J.1248.2013.145

Gupta H v., Kling H, Yilmaz KK, Martinez GF (2009) Decomposition of the mean squared error and NSE performance criteria: Implications for improving hydrological modelling. Journal of Hydrology. https://doi.org/10.1016/j.jhydrol.2009.08.003

Gusain A, Ghosh S, Karmakar S (2020a) Added value of CMIP6 over CMIP5 models in simulating Indian summer monsoon rainfall. Atmospheric Research 232:. https://doi.org/10.1016/j.atmosres.2019.104680

Gusain A, Ghosh S, Karmakar S (2020b) Added value of CMIP6 over CMIP5 models in simulating Indian summer monsoon rainfall. Atmospheric Research. https://doi.org/10.1016/j.atmosres.2019.104680

Heinze C, Eyring V, Friedlingstein P, et al (2019) ESD Reviews: Climate feedbacks in the Earth system and prospects for their evaluation. Earth System Dynamics

Hijmans RJ, Cameron SE, Parra JL, et al (2005) Very high resolution interpolated climate surfaces for global land areas. International Journal of Climatology. https://doi.org/10.1002/joc.1276

Ipcc (2013) Working Group I Contribution to the IPCC Fifth Assessment Report - Summary for Policymakers. Climate Change 2013: The Physical Science Basis. https://doi.org/10.1017/CBO9781107415324.004

Jain S, Salunke P, Mishra SK, Sahany S (2019) Performance of CMIP5 models in the simulation of Indian summer monsoon. Theoretical and Applied Climatology. https://doi.org/10.1007/s00704-0182674-3

Johnson F, Westra S, Sharma A, Pitman AJ (2011) An assessment of GCM skill in simulating persistence across multiple time scales. Journal of Climate. https://doi.org/10.1175/2011JCLI3732.1

Kamruzzaman M, Hwang S, Cho J, et al (2019) Evaluating the spatiotemporal characteristics of agricultural drought in bangladesh using effective drought index. Water (Switzerland) 11:. https://doi.org/10.3390/W11122437

Kamworapan S, Surussavadee C (2019) Evaluation of CMIP5 global climate models for simulating climatological temperature and precipitation for southeast Asia. Advances in Meteorology. https://doi.org/10.1155/2019/1067365 
Khan MJU, Islam AKMS, Das MK, et al (2019) Observed trends in climate extremes over Bangladesh from 1981 to 2010. Climate Research. https://doi.org/10.3354/cr01539

Khan N, Shahid S, Ahmed K, et al (2018a) Performance assessment of general circulation model in simulating daily precipitation and temperature using multiple gridded datasets. Water (Switzerland) 10:. https://doi.org/10.3390/w10121793

Khan N, Shahid S, Ahmed K, et al (2018b) Performance assessment of general circulation model in simulating daily precipitation and temperature using multiple gridded datasets. Water (Switzerland). https://doi.org/10.3390/w10121793

Kling H, Fuchs M, Paulin M (2012) Runoff conditions in the upper Danube basin under an ensemble of climate change scenarios. Journal of Hydrology. https://doi.org/10.1016/j.jhydrol.2012.01.011

Koch J, Demirel MC, Stisen S (2018) The SPAtial EFficiency metric (SPAEF): multiple-component evaluation of spatial patterns for optimization of hydrological models. Geoscientific Model Development 11:1873-1886. https://doi.org/10.5194/gmd-11-1873-2018

Lin CY, Tung CP (2017) Procedure for selecting GCM datasets for climate risk assessment. Terrestrial, Atmospheric and Oceanic Sciences. https://doi.org/10.3319/TAO.2016.06.14.01(CCA)

Lutz AF, ter Maat HW, Biemans H, et al (2016) Selecting representative climate models for climate change impact studies: an advanced envelope-based selection approach. International Journal of Climatology. https://doi.org/10.1002/joc.4608

Maxino CC, McAvaney BJ, Pitman AJ, Perkins SE (2008) Ranking the AR4 climate models over the Murray-Darling Basin using simulated maximum temperature, minimum temperature and precipitation. International Journal of Climatology. https://doi.org/10.1002/joc.1612

McMahon TA, Peel MC, Karoly DJ (2015) Assessment of precipitation and temperature data from CMIP3 global climate models for hydrologic simulation. Hydrology and Earth System Sciences. https://doi.org/10.5194/hess-19-361-2015

Meehl GA, Covey C, Delworth T, et al (2007) The WCRP CMIP3 multimodel dataset: A new era in climatic change research. Bulletin of the American Meteorological Society. https://doi.org/10.1175/BAMS88-9-1383

Mohsenipour M, Shahid S, Chung E sung, Wang X jun (2018) Changing Pattern of Droughts during Cropping Seasons of Bangladesh. Water Resources Management. https://doi.org/10.1007/s11269017-1890-4

Nashwan MS, Shahid S (2020) A novel framework for selecting general circulation models based on the spatial patterns of climate. International Journal of Climatology 40:4422-4443. https://doi.org/10.1002/joc.6465

Nashwan MS, Shahid S, Wang X (2019) Assessment of satellite-based precipitation measurement products over the hot desert climate of Egypt. Remote Sensing. https://doi.org/10.3390/rs11050555 
Nie S, Fu S, Cao W, Jia X (2020) Comparison of monthly air and land surface temperature extremes simulated using CMIP5 and CMIP6 versions of the Beijing Climate Center climate model. Theoretical and Applied Climatology. https://doi.org/10.1007/s00704-020-03090-x

Northrop PJ (2013) Comments on "A simple, coherent framework for partitioning uncertainty in climate predictions." Journal of Climate

Ogata T, Ueda H, Inoue T, et al (2014) Projected future changes in the Asian monsoon: A comparison of CMIP3 and CMIP5 model results. Journal of the Meteorological Society of Japan. https://doi.org/10.2151/jmsj.2014-302

O'Neill BC, Kriegler E, Riahi K, et al (2014) A new scenario framework for climate change research: The concept of shared socioeconomic pathways. Climatic Change. https://doi.org/10.1007/s10584-0130905-2

Pathak R, Sahany S, Mishra SK, Dash SK (2019) Precipitation Biases in CMIP5 Models over the South Asian Region. Scientific Reports. https://doi.org/10.1038/s41598-019-45907-4

Perkins SE, Pitman AJ, Holbrook NJ, McAneney J (2007) Evaluation of the AR4 climate models' simulated daily maximum temperature, minimum temperature, and precipitation over Australia using probability density functions. Journal of Climate. https://doi.org/10.1175/JCLI4253.1

Raju KS, Kumar DN (2014) Ranking of global climate models for India using multicriterion analysis. Climate Research. https://doi.org/10.3354/cr01222

Raju KS, Kumar DN (2020) Review of approaches for selection and ensembling of GCMS. Journal of Water and Climate Change 11:577-599. https://doi.org/10.2166/wcc.2020.128

Rivera JA, Arnould G (2020) Evaluation of the ability of CMIP6 models to simulate precipitation over Southwestern South America: Climatic features and long-term trends (1901-2014). Atmospheric Research. https://doi.org/10.1016/j.atmosres.2020.104953

Sa'adi Z, Shahid S, Chung ES, Ismail T bin (2017) Projection of spatial and temporal changes of rainfall in Sarawak of Borneo Island using statistical downscaling of CMIP5 models. Atmospheric Research. https://doi.org/10.1016/j.atmosres.2017.08.002

Salman SA, Shahid S, Ismail T, et al (2018) Selection of climate models for projection of spatiotemporal changes in temperature of Iraq with uncertainties. Atmospheric Research. https://doi.org/10.1016/j.atmosres.2018.07.008

Shashikanth K, Salvi K, Ghosh S, Rajendran K (2014) Do CMIP5 simulations of Indian summer monsoon rainfall differ from those of CMIP3? Atmospheric Science Letters. https://doi.org/10.1002/as/2.466

Shiru MS, Shahid S, Dewan A, et al (2020) Projection of meteorological droughts in Nigeria during growing seasons under climate change scenarios. Scientific Reports. https://doi.org/10.1038/s41598-020-67146-8

Solomon, S. D, Qin M, Manning Z, et al (2007) Summary for Policymakers. In: Climate Change 2007: The Physical Science Basis. Contribution of Working Group I to the Fourth Assessment Report of the 
Intergovernmental Panel on Climate Change. D Qin M Manning Z Chen M Marquis K Averyt M Tignor and HL Miller New York Cambridge University Press pp. https://doi.org/10.1038/446727a

Song YH, Nashwan MS, Chung ES, Shahid S (2021) Advances in CMIP6 INM-CM5 over CMIP5 INM-CM4 for precipitation simulation in South Korea. Atmospheric Research. https://doi.org/10.1016/j.atmosres.2020.105261

Sperber KR, Annamalai H, Kang IS, et al (2013) The Asian summer monsoon: An intercomparison of CMIP5 vs. CMIP3 simulations of the late 20th century. Climate Dynamics. https://doi.org/10.1007/s00382-012-1607-6

Sun Q, Miao C, Duan Q, et al (2018) A Review of Global Precipitation Data Sets: Data Sources, Estimation, and Intercomparisons. Reviews of Geophysics. https://doi.org/10.1002/2017RG000574

Taylor KE (2001) Summarizing multiple aspects of model performance in a single diagram. Journal of Geophysical Research Atmospheres. https://doi.org/10.1029/2000JD900719

Taylor KE, Stouffer RJ, Meehl GA (2012) An overview of CMIP5 and the experiment design. Bulletin of the American Meteorological Society

Tiwari PR, Kar SC, Mohanty UC, et al (2014) Skill of precipitation prediction with GCMs over north India during winter season. International Journal of Climatology. https://doi.org/10.1002/joc.3921

Tokarska KB, Stolpe MB, Sippel S, et al (2020) Past warming trend constrains future warming in CMIP6 models. Science Advances. https://doi.org/10.1126/sciadv.aaz9549

van Vuuren DP, Riahi K (2011) The relationship between short-term emissions and long-term concentration targets. Climatic Change

Wu T, Lu Y, Fang Y, et al (2019) The Beijing Climate Center Climate System Model (BCC-CSM): the main progress from CMIP5 to CMIP6. Geoscientific Model Development 12:1573-1600. https://doi.org/10.5194/gmd-12-1573-2019

Zamani Y, Hashemi Monfared SA, Azhdari moghaddam M, Hamidianpour M (2020) A comparison of CMIP6 and CMIP5 projections for precipitation to observational data: the case of Northeastern Iran. Theoretical and Applied Climatology 142:1613-1623. https://doi.org/10.1007/s00704-02003406-x

Zambrano-Bigiarini M, Nauditt A, Birkel C, et al (2017) Temporal and spatial evaluation of satellite-based rainfall estimates across the complex topographical and climatic gradients of Chile. Hydrology and Earth System Sciences. https://doi.org/10.5194/hess-21-1295-2017

Zelinka MD, Myers TA, McCoy DT, et al (2020) Causes of Higher Climate Sensitivity in CMIP6 Models. Geophysical Research Letters. https://doi.org/10.1029/2019GL085782

Zhou T, Li Z (2002) Simulation of the East Asian summer monsoon using a variable resolution atmospheric GCM. Climate Dynamics. https://doi.org/10.1007/s00382-001-0214-8 
Zhu YY, Yang S (2020) Evaluation of CMIP6 for historical temperature and precipitation over the Tibetan Plateau and its comparison with CMIP5. Advances in Climate Change Research.

https://doi.org/10.1016/j.accre.2020.08.001 


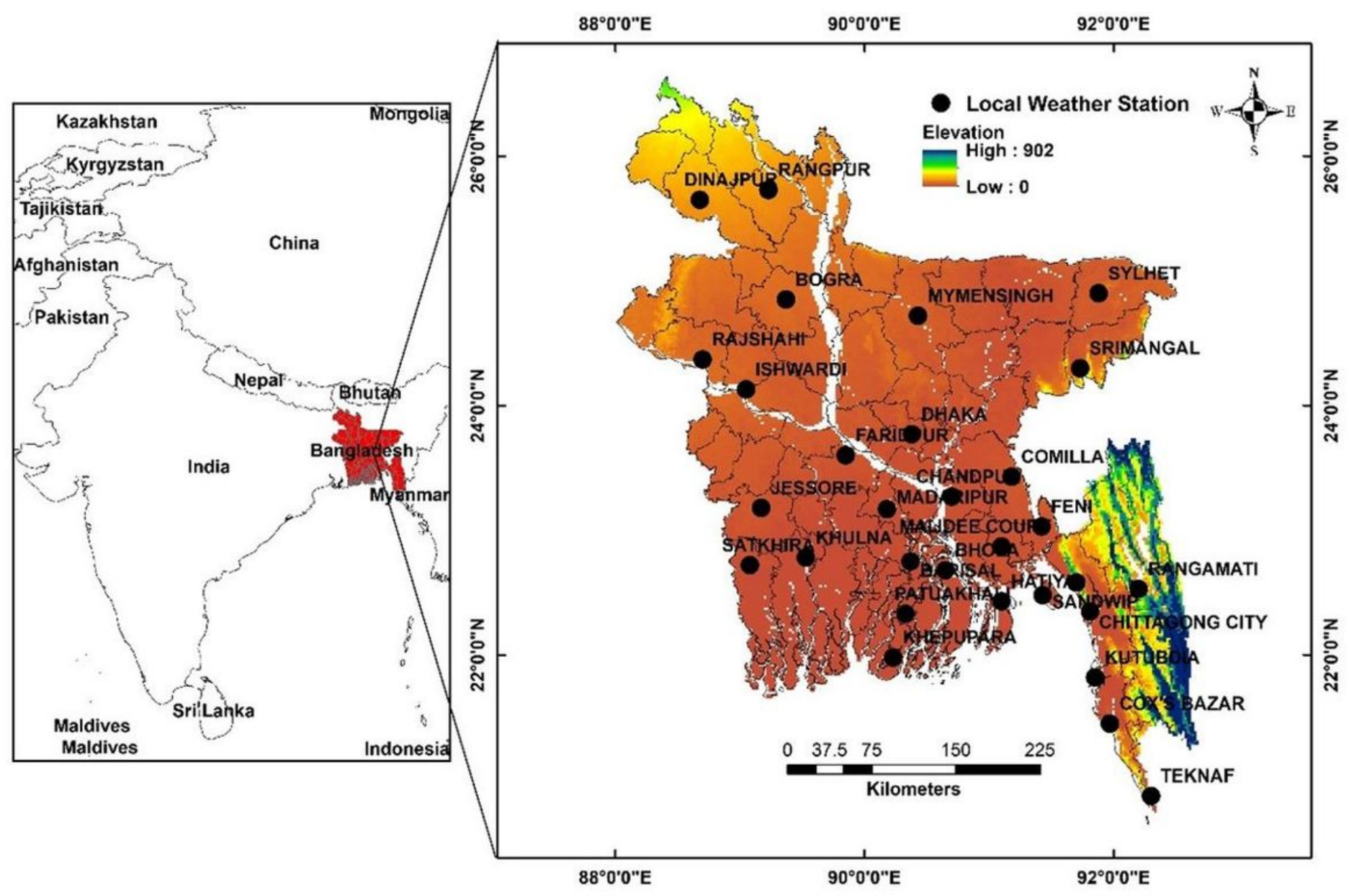

Figure 1

Location of meteorological stations and elevation map of Bangladesh. Note: The designations employed and the presentation of the material on this map do not imply the expression of any opinion whatsoever on the part of Research Square concerning the legal status of any country, territory, city or area or of its authorities, or concerning the delimitation of its frontiers or boundaries. This map has been provided by the authors. 
(a) OBS

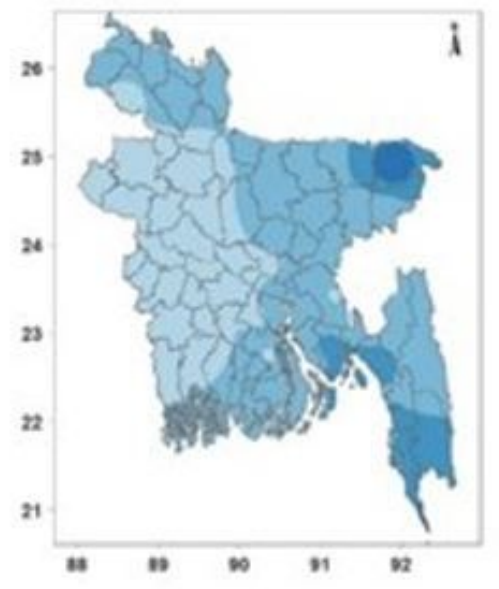

(b) CMIPS MME

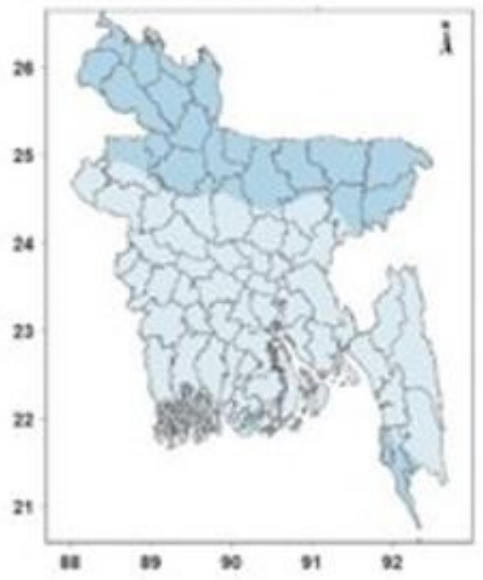

(C) CMIP6 MME

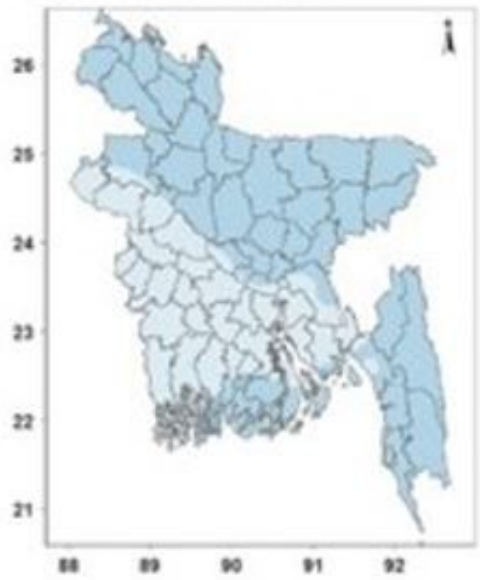

\section{Precipitation ( $\mathrm{mm} /$ day)}

\section{0 to $2 \quad 2$ to $4 \quad 4$ to $6 \quad 6$ to $8 \quad 8$ to 1010 to 12}

\section{(d) CMIP5 MME-OBS}

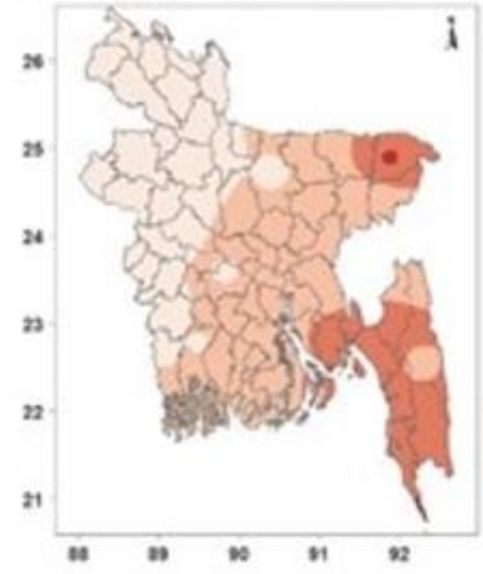

(e) CMIP6 MME-OBS

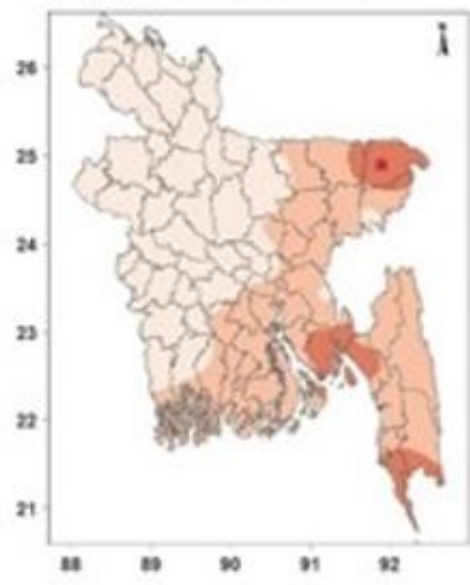

(f) CMIP6 MME-CMIP5 MME

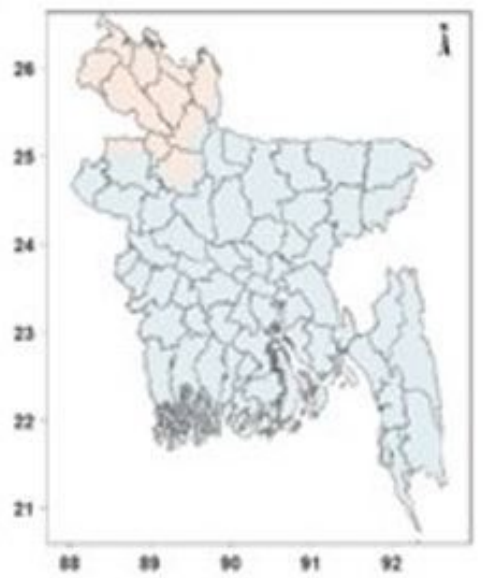

\section{Precipitation ( $\mathrm{mm} /$ day)}

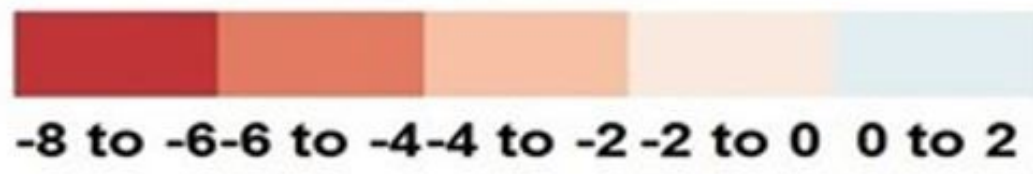

Figure 2

Spatial distribution of mean annual precipitation (mm®day-1) for 1977-2005 in (a) Observed, (b) CMIP5 MME, (c) CMIP6 MME. The difference of precipitation (b) between the CMIP5 MME and the observation, (d) between the CMIP6 MME and the observation, (f) between the CMIP6 MME and CMIP5 MME. CMIP5, Phase 5 of the Coupled Model Intercomparison Project; CMIP6, Phase 6 of the Coupled Model Intercomparison Project; MME, multimodel ensemble. Note: The designations employed and the 
presentation of the material on this map do not imply the expression of any opinion whatsoever on the part of Research Square concerning the legal status of any country, territory, city or area or of its authorities, or concerning the delimitation of its frontiers or boundaries. This map has been provided by the authors.

(a) Annual

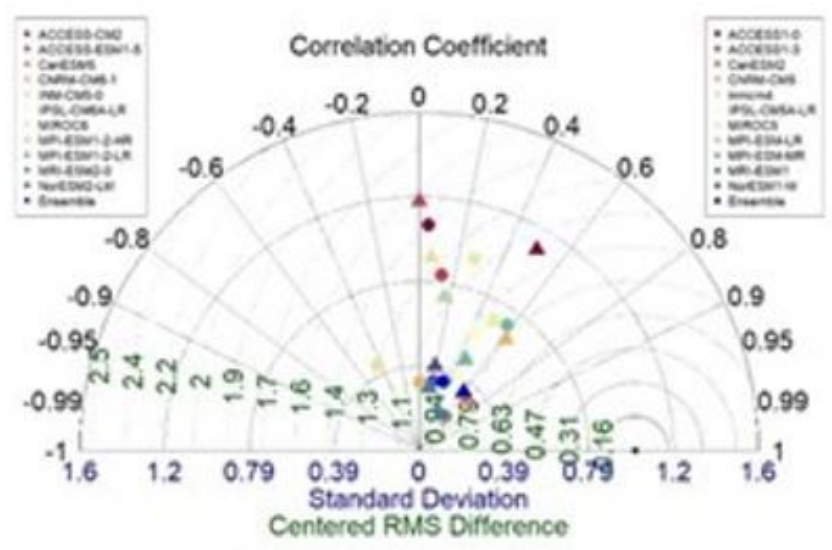

(c) Pre-monsoon

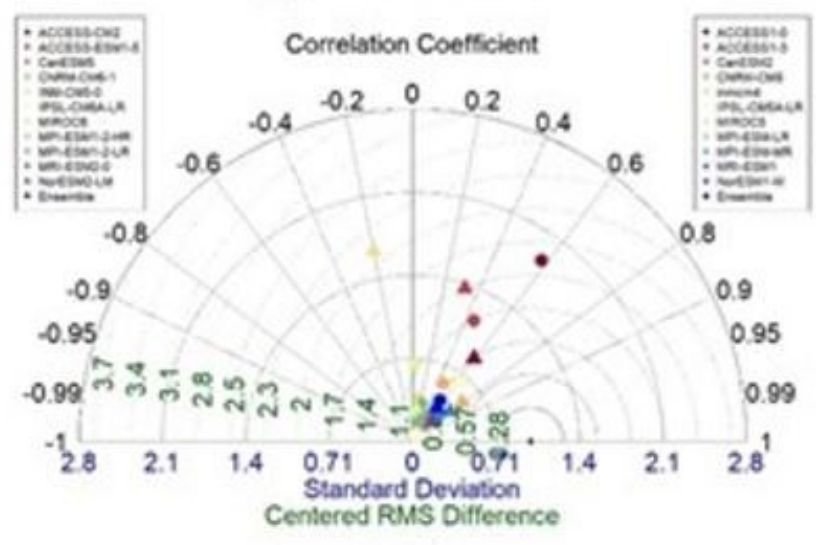

(b) Monsoon

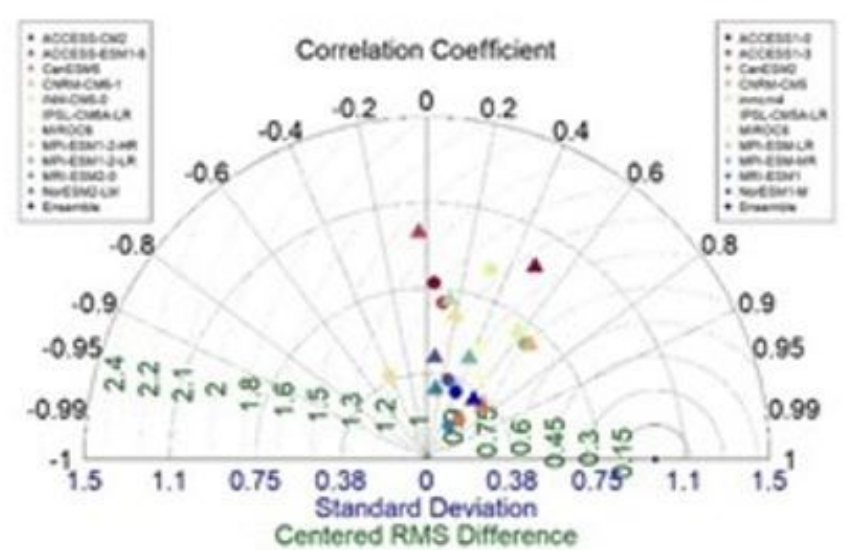

\section{(d) Post-monsoon}

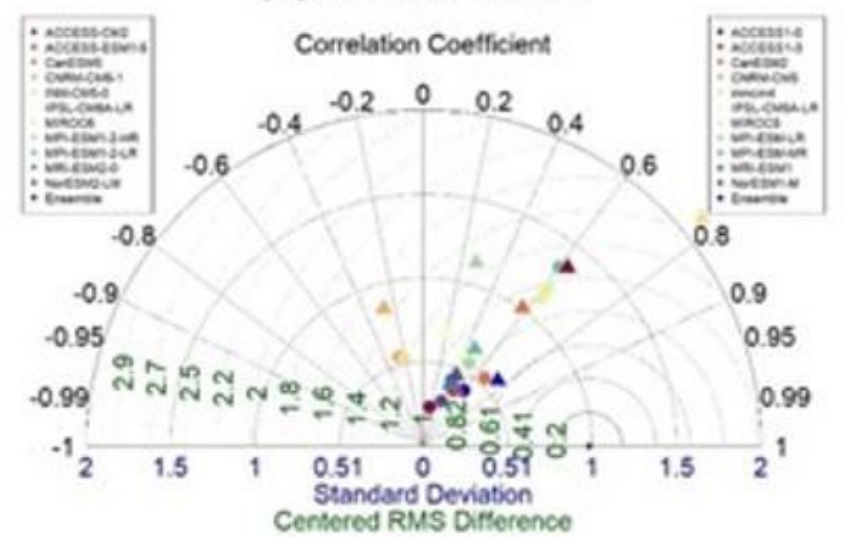

(e) Winter

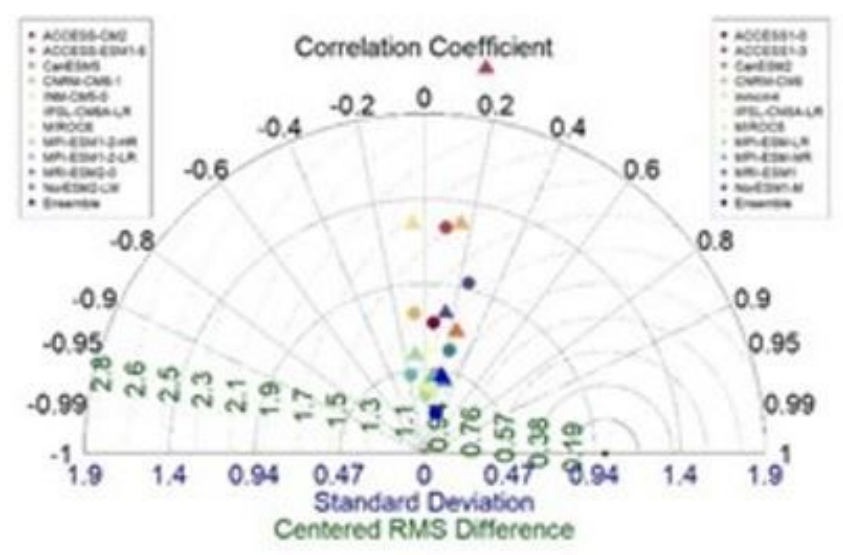

\section{Figure 3}

Taylor diagrams displaying normalized pattern statistics of climatological (a) annual, (b) Monsoon, (c) Pre-monsoon, (d) Post-monsoon, and (e) Winter precipitation over Bangladesh between 11 GCMs and 
observations for the period 1977-2005. Triangle and round symbols indicate CMIP5 and CMIP6 GCMs listed in Table 1, respectively.

(a) Annual

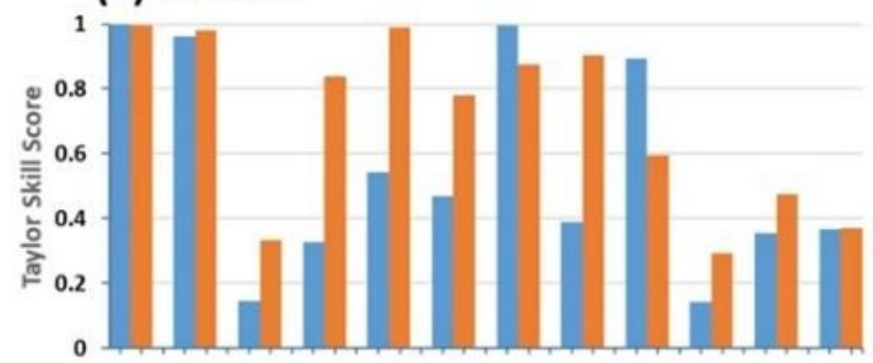

(c) Pre-monsoon

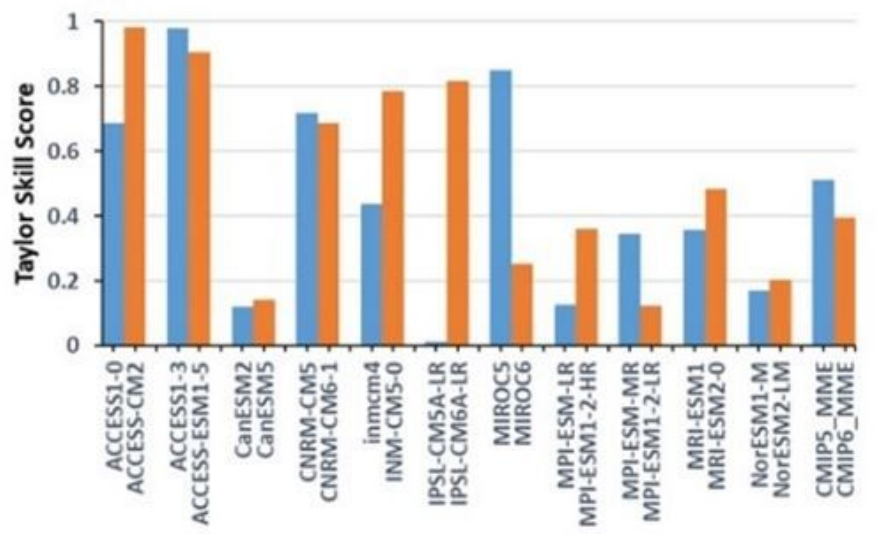

(b) Monsoon

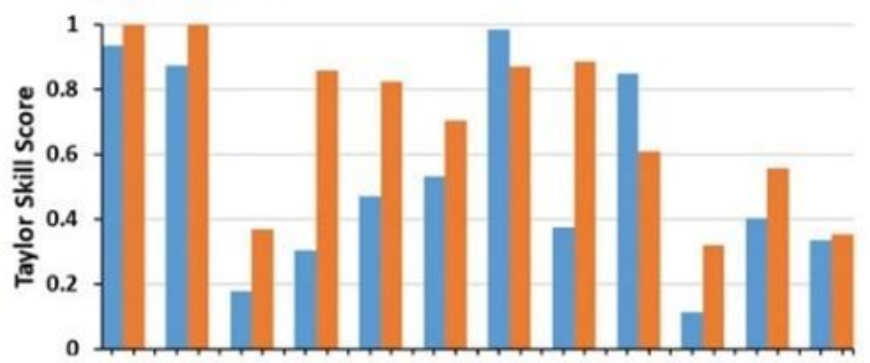

(d) Post-monsoon

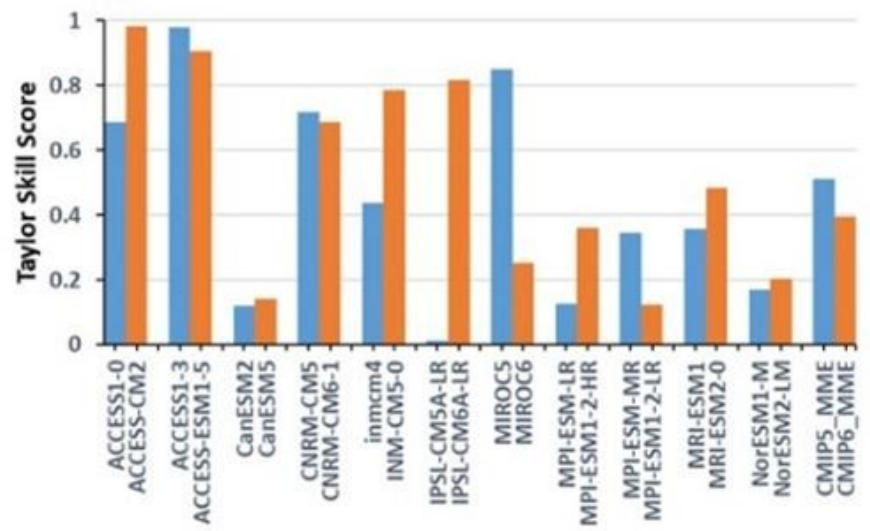

(e) Winter

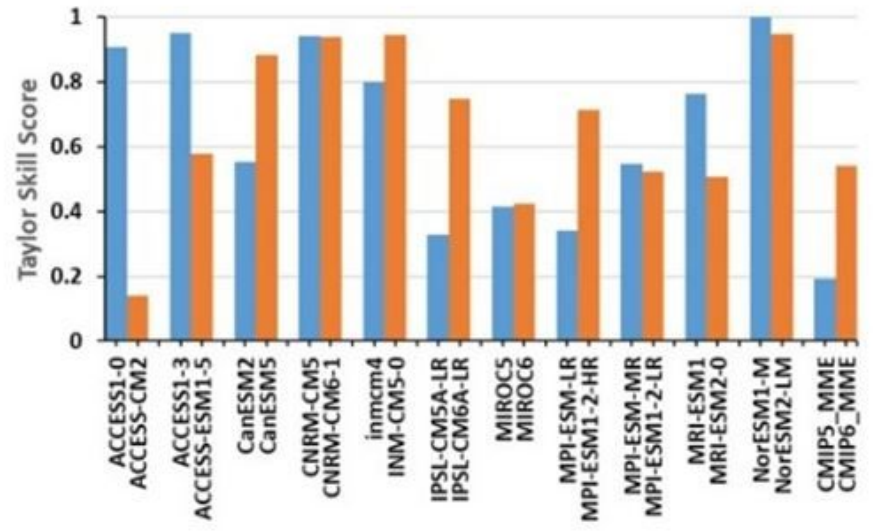

CMIP5 Models CMIP6 Models

\section{Figure 4}

Skill scores of the climatology of (a) annual, (b) pre-monsoon, (c) monsoon, (d) post-monsoon, and (e) winter precipitation in each model and the MME from CMIP5 and (b) CMIP6 models. CMIP5, Phase 5 of the Coupled Model Intercomparison Project; CMIP6, Phase 6 of the Coupled Model Intercomparison Project; MME, multimodel ensemble 
(a) OBS

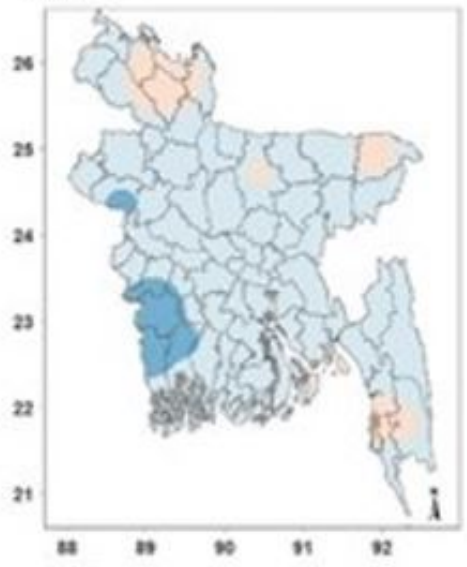

(b) CMIPS MME

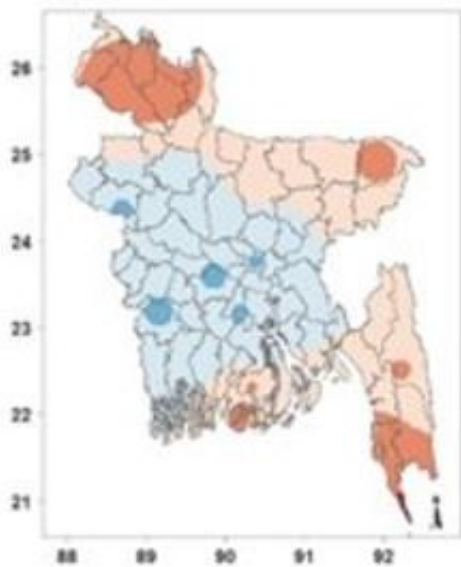

(C) CMIP6 MME

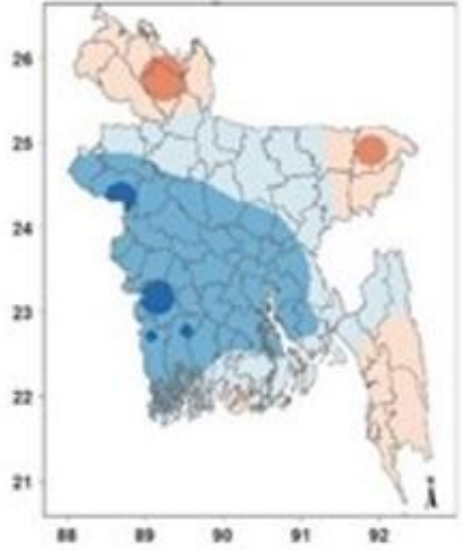

\section{Maximum temperature $\left({ }^{\circ} \mathrm{C}\right)$}

\section{7 to 2828 to 2929 to 3030 to 3131 to 3232 to 33}

(d) CMIPS MME-OBS

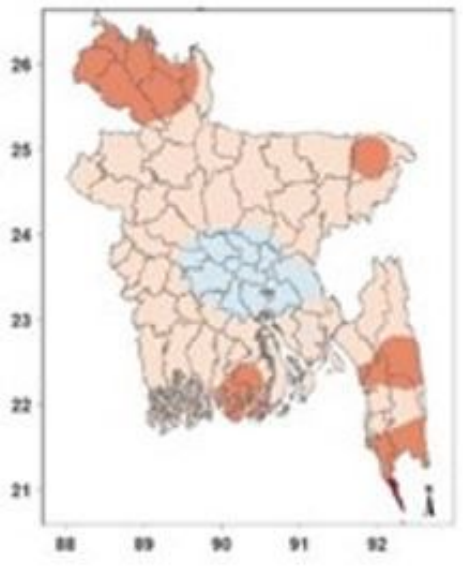

(e) CMIP6 MME-OBS

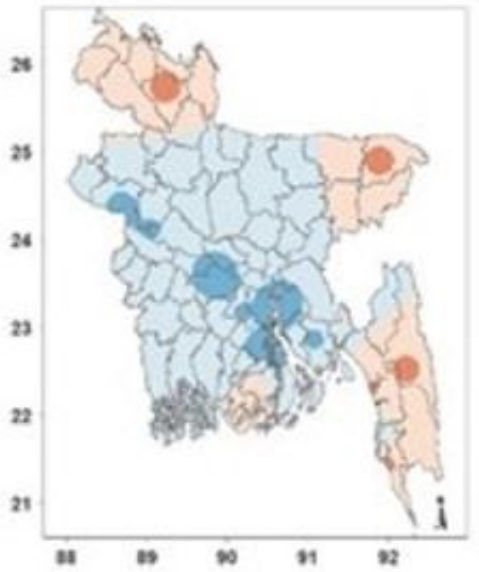

(f) CMIP6 MME-CMIPS MME

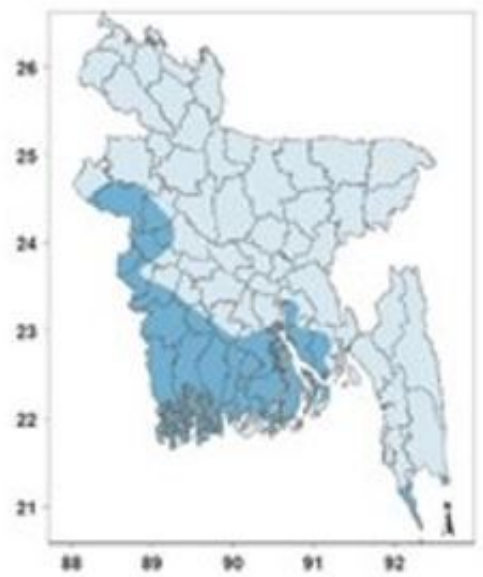

\section{Maximum temperature $\left({ }^{\circ} \mathrm{C}\right)$}

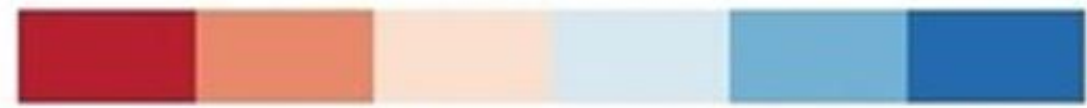

\section{-3 to $-2-2$ to $-1-1$ to 00 to 11 to 22 to 3}

\section{Figure 5}

As in Fig. 2, but for maximum temperature. Note: The designations employed and the presentation of the material on this map do not imply the expression of any opinion whatsoever on the part of Research Square concerning the legal status of any country, territory, city or area or of its authorities, or concerning the delimitation of its frontiers or boundaries. This map has been provided by the authors. 
(a) Annual

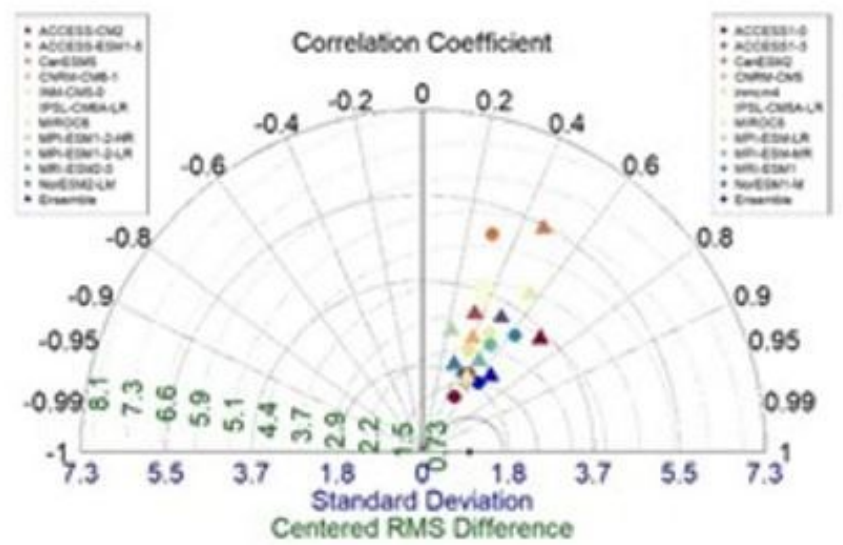

\section{(c) Pre-monsoon}

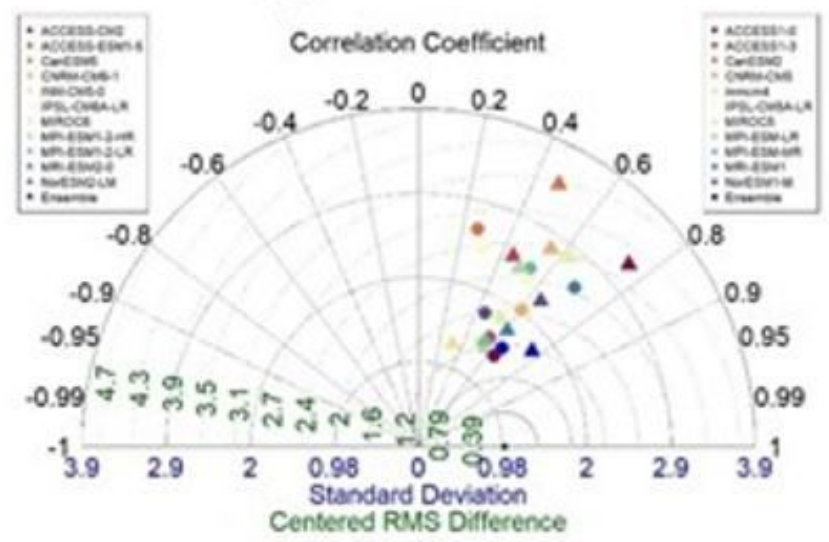

(b) Monsoon

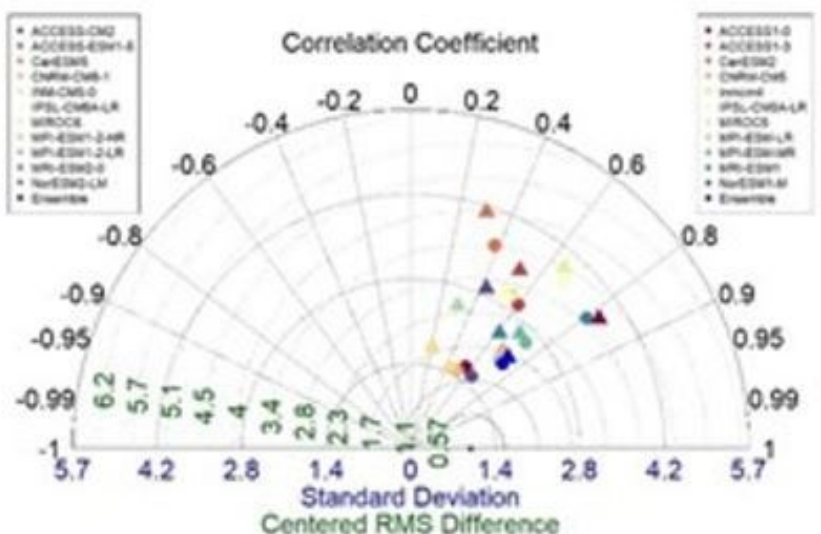

(d) Post-monsoon

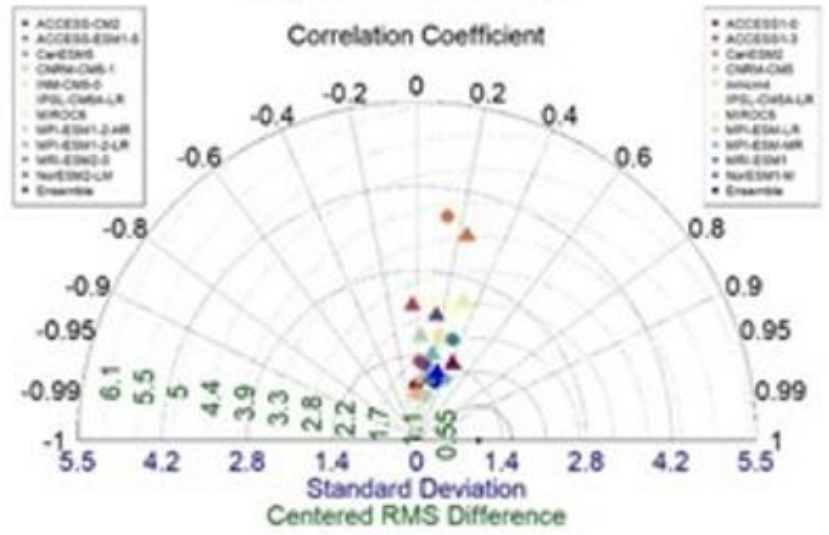

(e) Winter

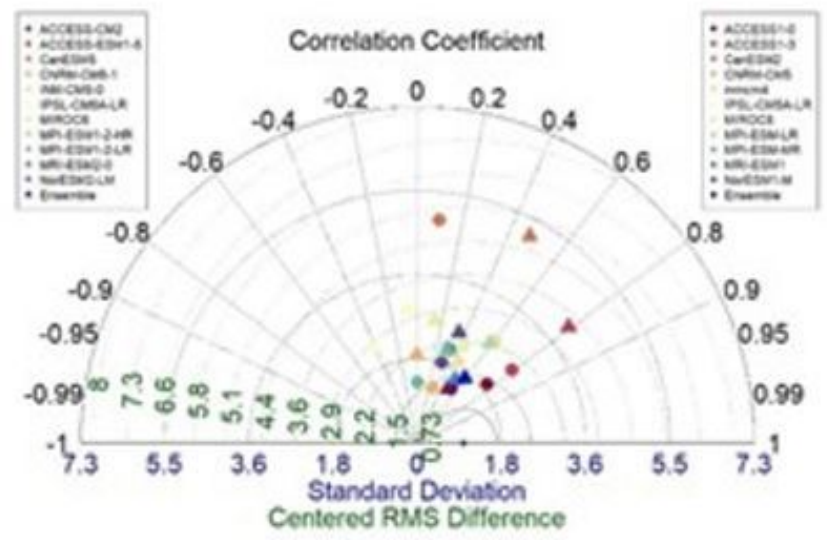

Figure 6

As in Fig. 3, but for maximum temperature 
(a) Annual

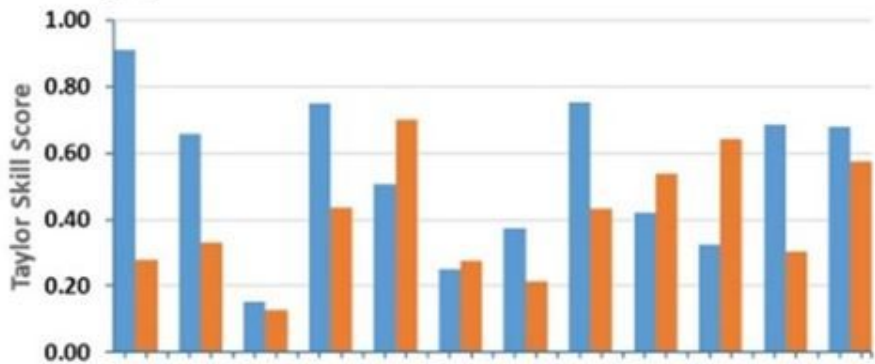

(c) Pre-monsoon

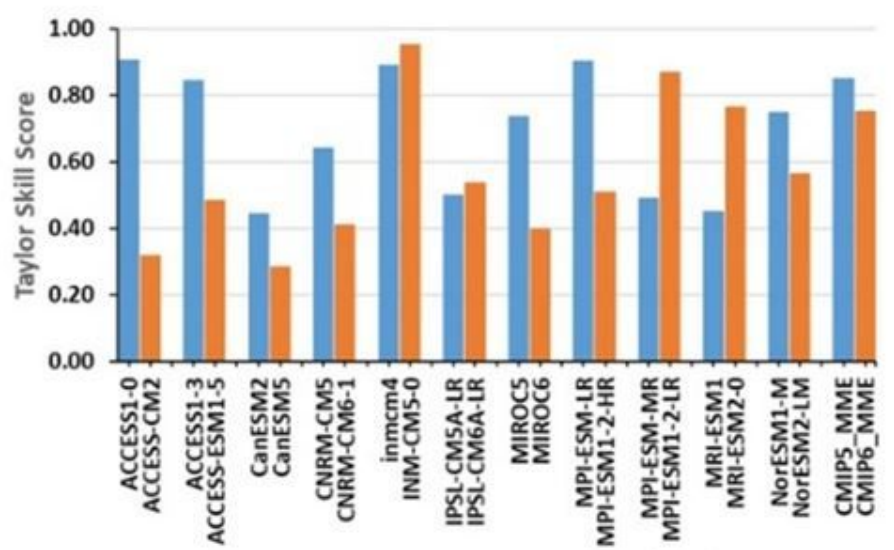

(e) Winter (b) Monsoon

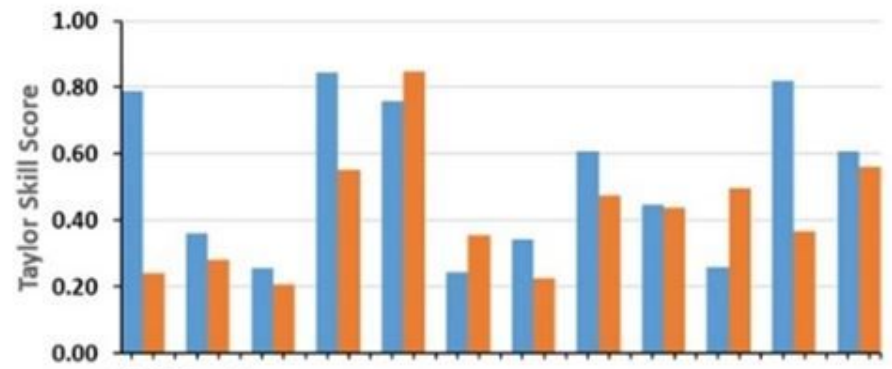

(d) Post-monsoon

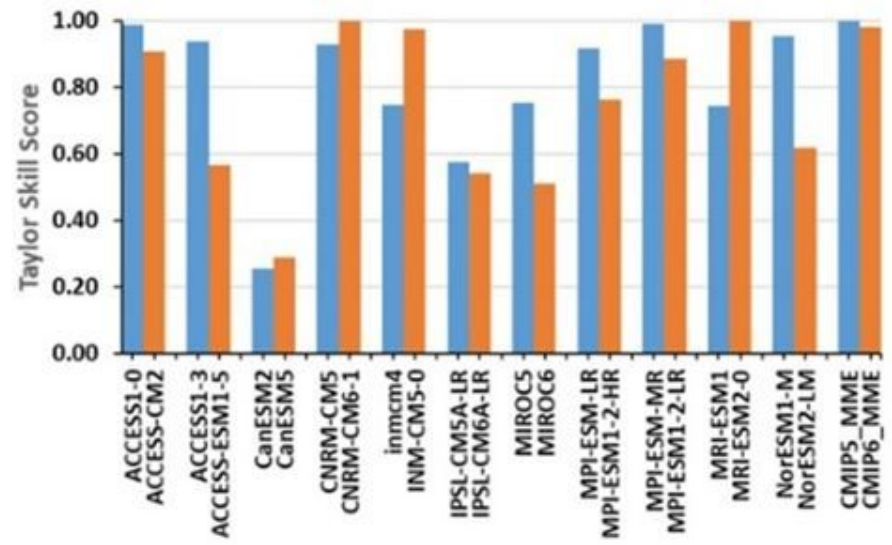

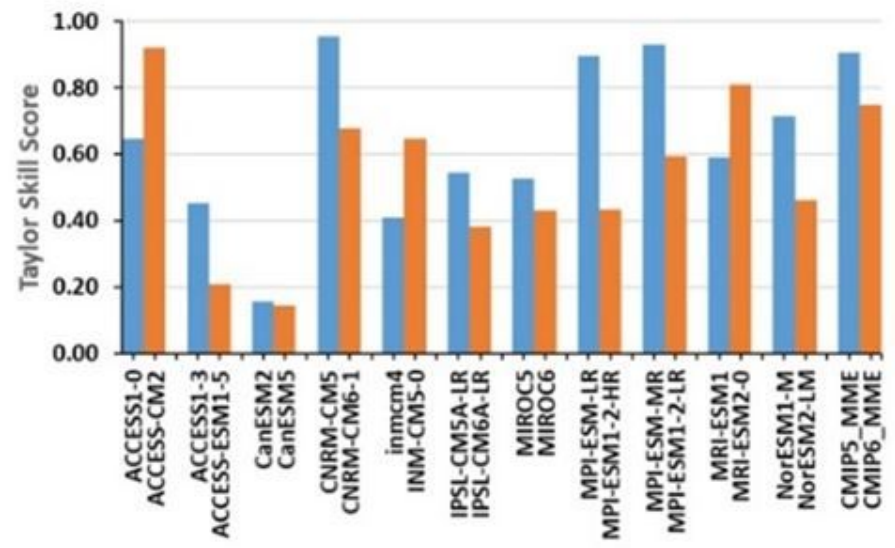

Figure 7

As in Fig. 4, but for maximum temperature 
(a) OBS

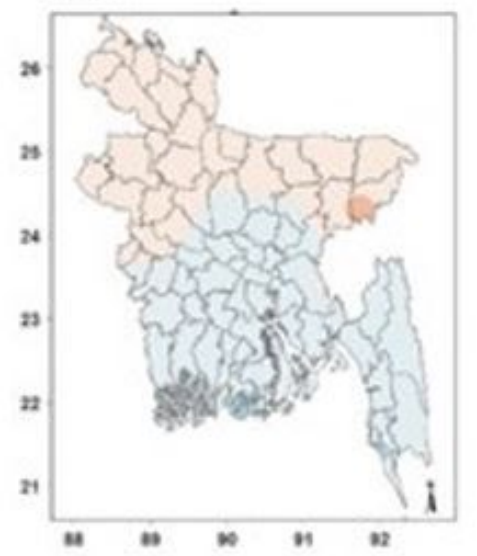

(b) CMIPS MME

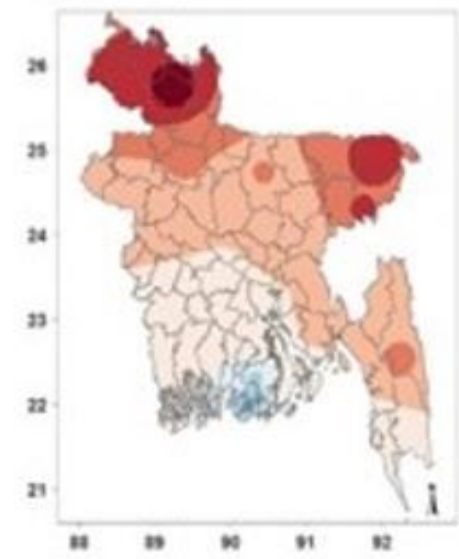

(C) CMIP6 MME

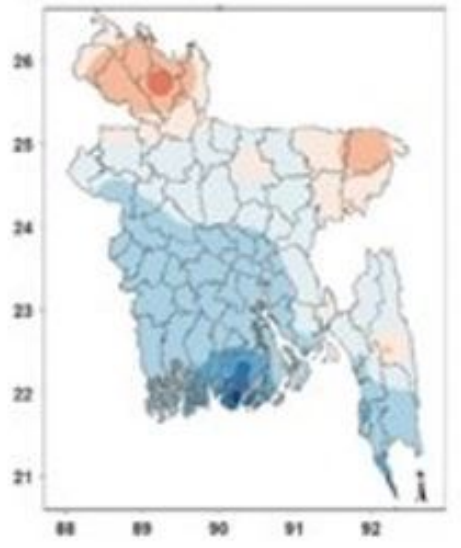

\section{Minimum temperature $\left({ }^{\circ} \mathrm{C}\right)$}

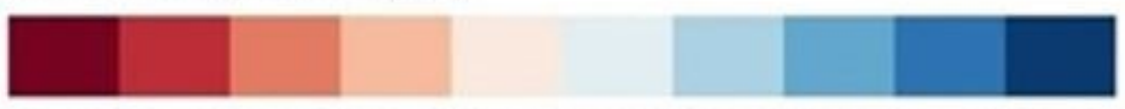

16 to 1717 to 1818 to 1919 to 2020 to 2121 to 2222 to 2323 to 2424 to 2525 to 26

(d) CMIP5 MME-OBS

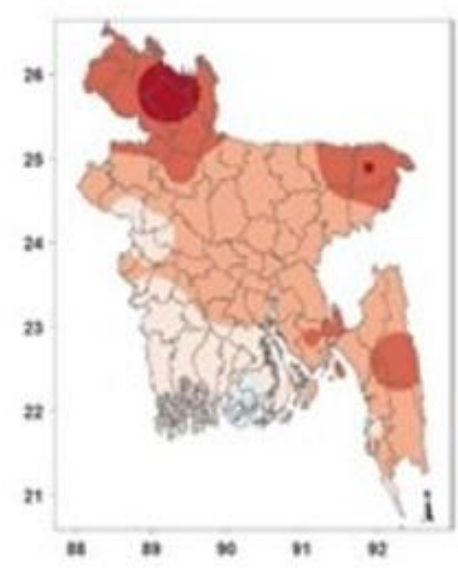

(e) CMIP6 MME-OBS

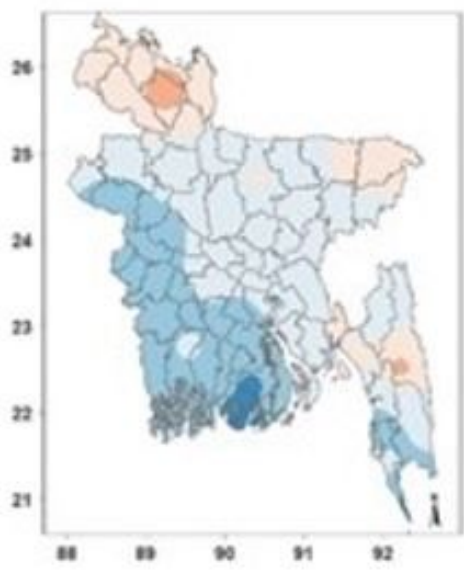

(f) CMIP5 MME-CMIP6 MME

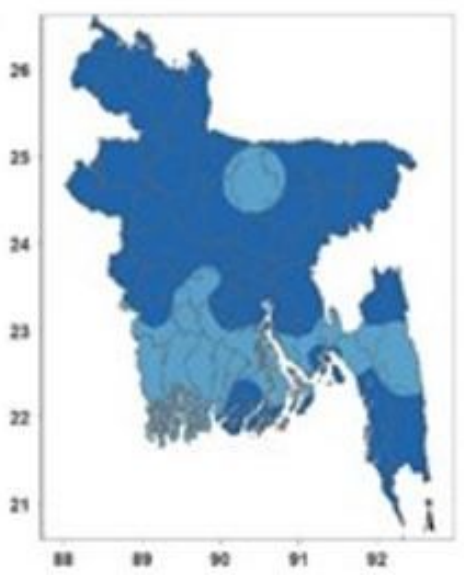

\section{Minimum temperature $\left({ }^{\circ} \mathrm{C}\right)$}
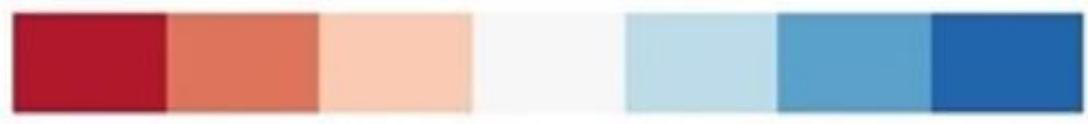

-4 to $-3-3$ to $-2-2$ to $-1-1$ to 00 to 11 to 22 to 3

\section{Figure 8}

As in Fig. 2, but for minimum temperature. Note: The designations employed and the presentation of the material on this map do not imply the expression of any opinion whatsoever on the part of Research Square concerning the legal status of any country, territory, city or area or of its authorities, or concerning the delimitation of its frontiers or boundaries. This map has been provided by the authors. 
(a) Annual

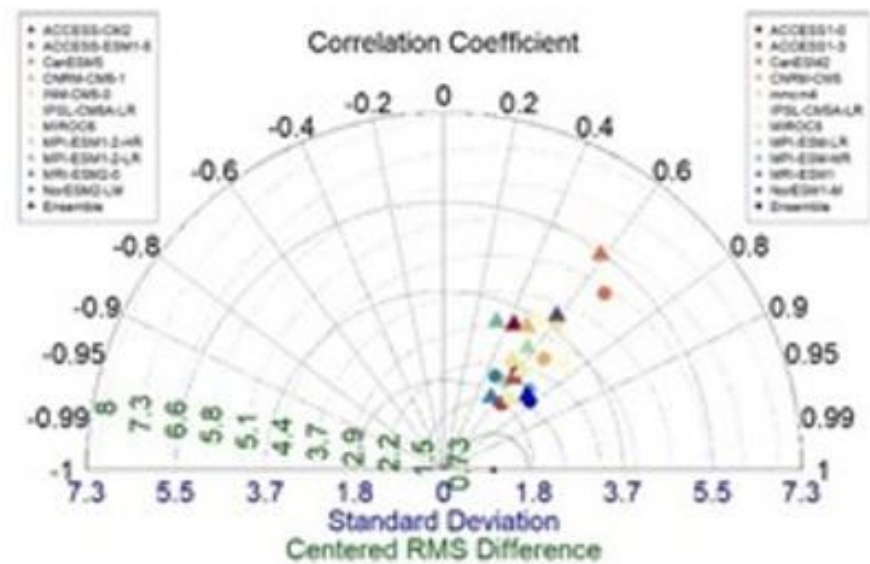

(c) Pre-monsoon

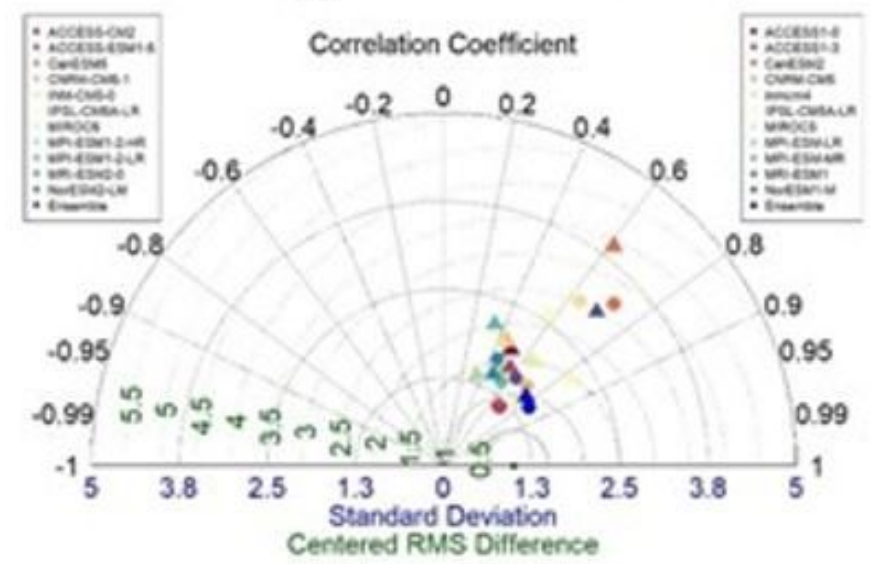

(b) Monsoon

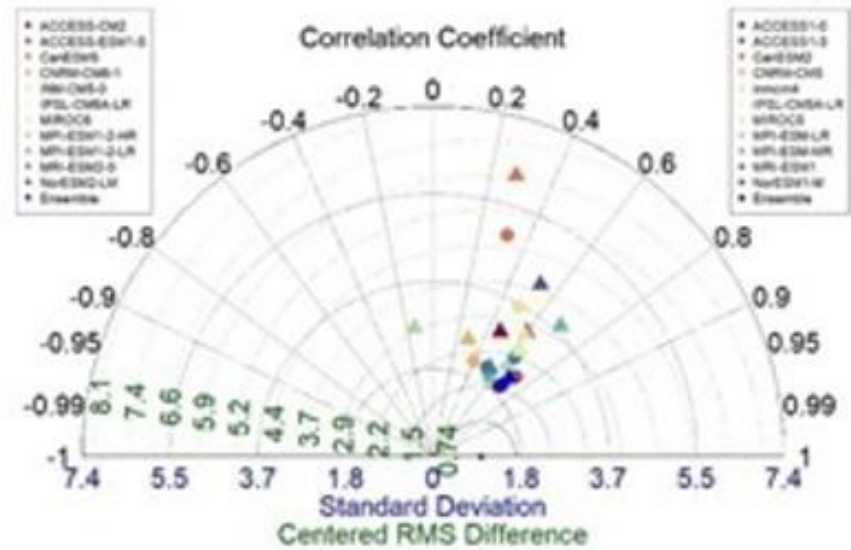

(d) Post-monsoon

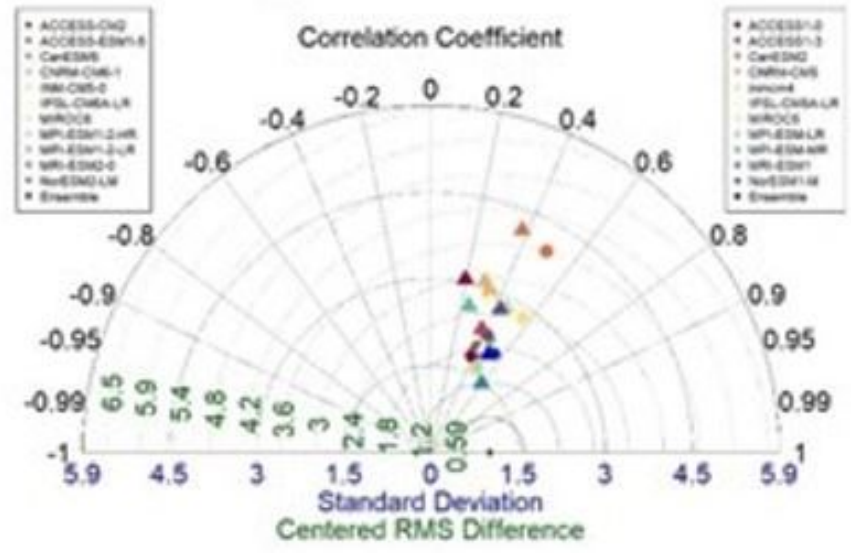

(e) Winter

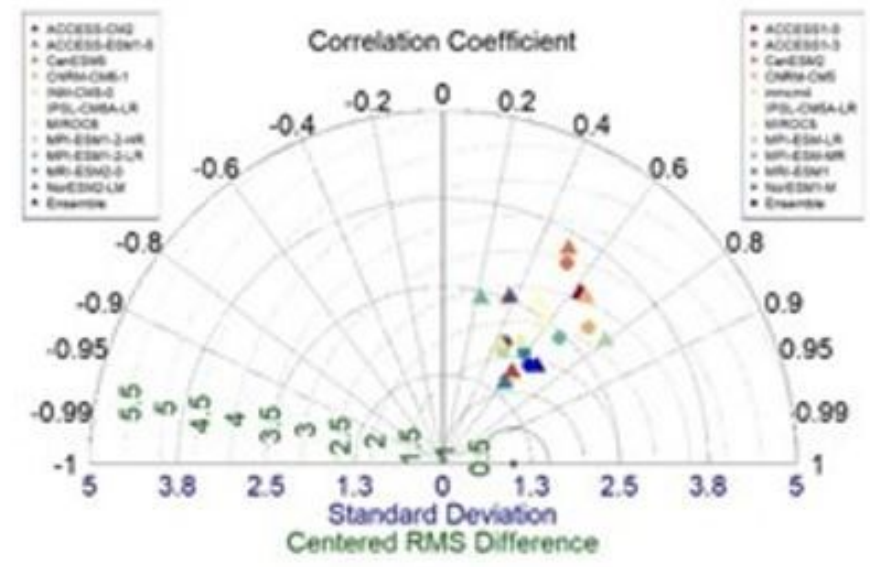

\section{Figure 9}

As in Fig. 3, but for minimum temperature 


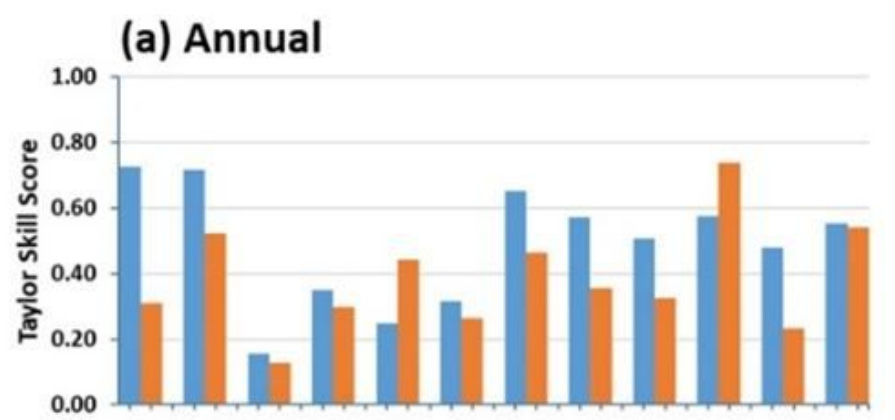

(c) Pre-monsoon

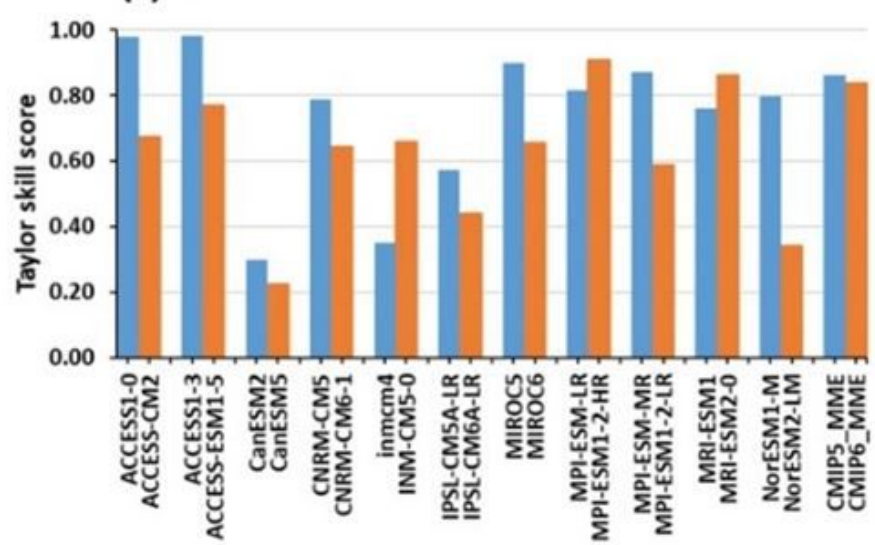

(b) Monsoon

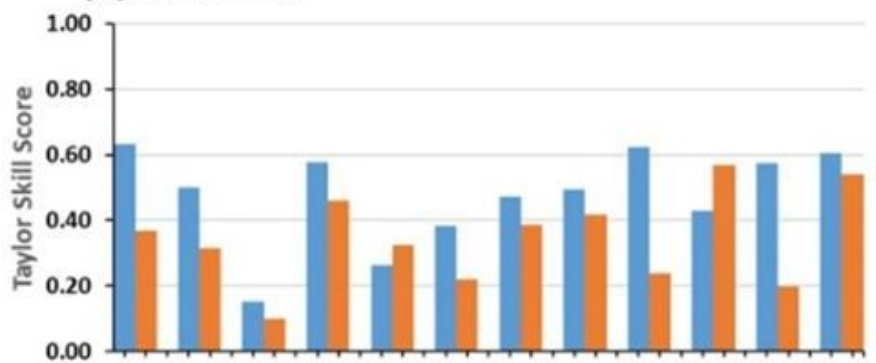

(d) Post-monsoon

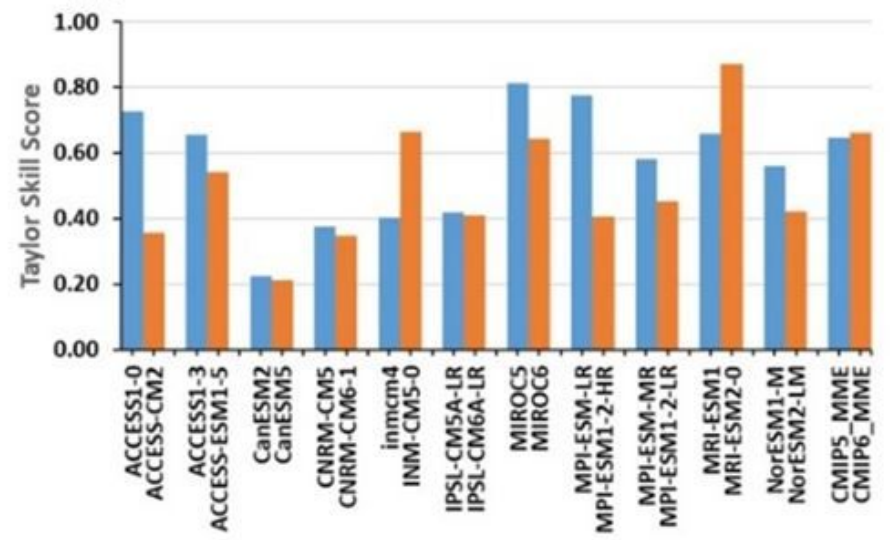

(e) Winter

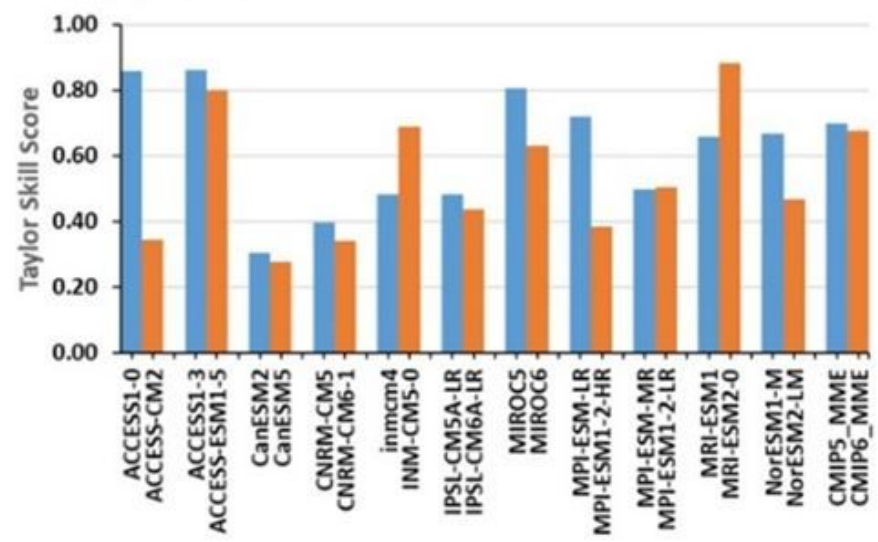

Figure 10

As in Fig. 4, but for minimum temperature

\section{Supplementary Files}

This is a list of supplementary files associated with this preprint. Click to download.

- Suppl.docx 